\title{
Operational sea passage scenario generation for virtual testing of ships using an optimization for simulation approach
}

\author{
Endre Sandvik ${ }^{1}$ Jørgen Bremnes Nielsen ${ }^{1} \cdot$ Bjørn Egil Asbjørnslett ${ }^{1} \cdot$ Eilif Pedersen $^{1} \cdot$ Kjetil Fagerholt $^{2}$
}

Received: 19 December 2018 / Accepted: 15 September 2020 / Published online: 20 November 2020

(c) The Author(s) 2020

\begin{abstract}
In this paper, a model for implementation of sea passage operational scenarios in the context of simulation-based design of ships is presented. To facilitate the transition towards more energy-efficient shipping, the ability to evaluate and understand ship and ship system behaviour in operational conditions is central. By introducing an optimization model in virtual testing frameworks, operational scenarios can be generated that enhances scenario relevance and testing abilities. The optimization for simulation approach provides speed and course commands based on an optimization framework which factors in the operational considerations and sea state conditions in the area of operation. Impact on the understanding of ship system performance using simulation is assessed in a case study where a sea passage over the North Pacific is replicated for varying operational scenarios and seasons. It is found that the variation of operational scenario, affecting the sea state and speed relation, causes significant differences in required power and fuel consumption estimates. Sea passage control is found to be an important dimension in virtual testing approaches.
\end{abstract}

Keywords Virtual testing $\cdot$ Virtual captain $\cdot$ Optimization for simulation $\cdot$ Sea passage scenario $\cdot$ Propulsion system

\section{List of symbols}

AIS

RPM

ETA

KVLCC2

MCR

RMS

$f_{\mathrm{c}}$

$\bar{f}_{\mathrm{c}}$

$h$

$n$

$n_{\mathrm{s}}$

$u_{\mathrm{p}}$

$s_{\mathrm{c}}$

$t$

Endre Sandvik

endre.sandvik91@gmail.com

1 Department of Marine Technology, Norwegian University of Science and Technology, Trondheim, Norway

2 Department of Industrial Economics and Technology Management, Norwegian University of Science and Technology, Trondheim, Norway

state

Weather forecast horizon

Number of candidate headings

Period between speed and heading

re-evaluations

Planned route segment $t \leq h$

Planning horizon time

$t_{\mathrm{c}}$
$t_{1-2}^{\mathrm{ga}}$
$v_{h}$
$v_{l}$
$v_{1-3}^{\mathrm{ga}}$
$v_{\mathrm{c}}$
dest
$\left(\operatorname{lat}_{\mathrm{c}}, \operatorname{lon}_{\mathrm{c}}\right)$
$\left(\operatorname{lat}_{\psi \mathrm{vst}}, \operatorname{lon}_{\psi \mathrm{vss}}\right)$
$\alpha$
$\tau_{r}$
$\kappa$
$\psi_{\mathrm{c}}$
$\Gamma$
$A_{\mathrm{r}}$
$C_{\mathrm{rt}}^{\mathrm{FH}}$
$C_{r}^{F}$
$D_{\mathrm{r}}$
$H_{\mathrm{s}}$
$R_{\psi v_{h} \mathrm{st}}$
$R_{\psi_{c} \eta_{n} s_{c} t}$
$R_{\psi \mathrm{vs}}^{\text {end }}$
$S$
$T_{\mathrm{r}}^{\mathrm{SL}}$

Current time

Speed profile time variables

Vessel speed $t \leq h$

Vessel speed $t>h$

Speed profile speed variables

New speed for simulation

Destination location

Current latitude and longitude

Fuel consumption rate in particular sea

Weighted average fuel consumption rate

Number of candidate segments $t \leq h$

Candidate route latitude and longitude

Wave propagation direction

Estimated delay on route $r$

Delay cost rate

New heading for simulation

Set of sea states in table look-up model

Distance to destination $t>h$

Fuel consumption per nautical mile $t \leq h$

Fuel consumption per nautical mile $t>h$

Waypoint distance $t \leq h$

Significant wave height

Set of candidate routes within forecast horizon

Route for speed profile optimization

End location for route $R_{\psi v_{h} \mathrm{st}}$ at $t=h$

Set of segments $t \leq h$

Delay route $r t \leq h$ 


$\begin{array}{ll}T_{\mathrm{p}} & \text { Spectral peak wave period } \\ T_{0} & \text { Target arrival time } \\ V & \text { Set of candidate vessel speeds } \\ V_{\text {rt }} & \text { Attainable speeds route } r t \leq h \\ V_{\text {att }} & \text { Attainable speed } \\ \bar{V}_{\text {att }} & \text { Expected attainable average speed } \\ V_{\text {att }}^{\text {its }} & \text { Attainable speed involuntary speed loss } \\ V_{\text {att }}^{\text {vsl }} & \text { Attainable speed voluntary speed loss } \\ V_{\text {req }} & \text { Requested speed } \\ W_{\text {rt }} & \text { Weather along route } r \text { at time } t \\ W_{x} & \text { Weather along route for } x \in X \\ X & \text { Decision variables speed profile } \\ & \text { optimization } \\ \Psi_{\text {max }} & \text { Maximum heading offset relative to great } \\ & \text { circle heading } \\ \Psi & \text { Set of candidate headings } \\ \text { V14 } 4 & \text { Scenario with target speed } 14 \text { knots and } \\ & \text { delay cost } 4 \text { tons/hour } \\ \text { Fixed14 } & \text { Scenario fixed route and target speed } 14 \\ & \text { knots }\end{array}$

\section{Introduction}

Energy-efficient shipping is a central topic in maritime research due to fluctuating fuel prices and stricter emission regulations. New technologies and operational measures have emerged which ship owners, designers and regulatory societies evaluate for application in current and future ships and fleets [1]. Propulsion system complexity increases with the introduction of new energy sources, prime movers and propulsion devices. The combination of limited track records for new systems, and the risk and cost of open ocean operation and investment cost for new ships and retrofitting, new technology is often met with hesitation and scepticism by ship owners, class societies and regulatory agents. In addition, the understanding of a system operating at calm water conditions is not necessarily transferable to operational conditions [2]. Hence, establishing evaluation methodologies capable of interpreting performance and revealing challenges in operational conditions is a key element in facilitating energy-efficient shipping. Virtual testing using simulation has been proposed as a solution to this problem. Simulation enables us to include and study factors, interactions and behaviour across domain boundaries in a dynamic environment, thus making it suitable for systems modelling and evaluation. This paper addresses the generation of relevant operational scenarios in which evaluation of ships and ship systems can be performed using simulation.

There are many challenges for developing and applying simulation models and frameworks for design of maritime systems. If the purpose is to evaluate the performance of a system in its operating environment, e.g. physical or economic environment, the relationship between the system and environmental state must be established. Typically, the resistance, motions and power production of a ship in operation are considered, requiring access to models capable of replicating both the relevant environmental factors and ship responses. Skjong et al. [3] address the application of distributed co-simulation for virtual prototyping of maritime systems and operations, focusing in particular on simulation frameworks for combining physical models for system performance evaluation. Simulation has in many cases also been applied to understand the level and variability of system environment impact on performance and operability. Bergström et al. [4] present a simulation-based approach to evaluate arctic transportation systems, where the occurrence and thickness of sea ice limits operation. Tillig et al. [5] describe a generic energy ship systems model for design and operation of ships and demonstrates its applicability in a simulation case study for a Panamax tanker. Sandvik et al. [6] present a simulation-based methodology for investigating ship design susceptibility towards operational delays during marine operations limited by the occurrence of operable weather windows. Bøckmann et al. [7] evaluate the fuel saving potential of retractable bow foils by simulating 1000 voyages for two routes in the North Atlantic. In these studies, the understanding of the system's ability to function in its operating environment is evaluated using long-term statistics of system factors. For stochastic environments, e.g. waves and sea ice occurrence, the intention is often to achieve converging measures of performance. However, considering the user's ability to control systems and the environment in simulation studies, an important question is how these assumptions and modelling efforts affect this convergence.

For a deep-sea vessel, the waves, wind and current the vessel will encounter during sea passage are not described in full by metocean statistics. The vessel's captain is in principle free to decide on any route he or she desires. There are however in most cases an operational context present which provides some constraints. Aarsæther and Moan [8] addresses the human element of navigation, presenting a human operator model and showing its effect on manoeuvring patterns using simulation. First of all, the economic and environmental consequences of poorly planned and executed route and speed management can be significant $[9$, 10]. The operations research community has for many years worked on weather routing algorithms, which provides recommendations for future route and speed. Such systems are found in most deep-sea vessels in operation today. Recent studies on weather routing algorithms can be found in e.g. [11-13]. For simulation scenario generation, the objective in the present work is however not to achieve scenarios where the occurring weather states are as calm as possible. A scenario must reflect the conditions ships encounter during operation, enabling observation of the performance and 
challenges inherent to proposed designs. The effect of route and speed decisions on ship performance is documented in several studies. Vettor and Guedes Soares [14-16] identify the major routes for the North Atlantic trades from voluntary observing ship data, and show that rough weather avoidance has a clear effect on the experienced wave climate. Jia et al. [17] show that the arrival requirements of ships in operation has a significant impact on emission characteristics. Thus, replicating a realistic wave climate and associated speeds is important for simulation scenario generation for investigating vessel capabilities and system requirements.

Automatic Identification System (AIS) data is a useful source of information for ship routes and corresponding speed levels. Combined with hindcast weather data ship sea passage behaviour can be replicated for computation of e.g. required power and fuel consumption. Bassam et al. [18] simulate the voyage of a tanker and an offshore service vessel using AIS data. However, the relevance of historic data is questionable if other ship designs and time instants are to be investigated as part of a simulation-based design approach. Where a vessel has been in the past, and at what speed, must be considered a consequence of operational and tactical navigation decisions. To achieve comparable scenarios using simulation, we argue that the relevant question is not "how" ships have been operated, but "why" in that particular manner. By developing a model capable of controlling operational and tactical navigation decisions, a causality enabling us to understand and replicate sea passage behaviour is achieved.

Decision processes are based on the intention of optimizing the outcome of a given scenario. Hence, optimization models are frequently applied to understand, evaluate and replicate decision processes. The combination of simulation and optimization models is currently done in several ways in the literature depending on the intended functionality. "Optimization for simulation" is a term describing a hierarchical relationship where the objective is to provide added value to the simulation, i.e. applying an optimization algorithm as a sub-routine in the simulation model [19]. A review of applications and algorithms for combinations of simulation and optimization models is found in [20].

To facilitate virtual testing of ships and ship systems, this paper presents a virtual captain simulation module for implementation of relevant sea passage scenarios. The novelty of this paper is the presentation of an optimization for simulation approach for replicating relevant operational scenarios in simulation studies, focusing in particular on the implications to ship system evaluation in simulation-based design. This research is to be considered part of the validation effort for models evaluating ship performance in waves. Previous research has provided knowledge for how route and speed influence voyage fuel consumption and power demand, and how arrival requirements is an important factor for route and speed management. Further, operations research provide optimization algorithms for the decision process in weather routing, which can be combined with simulation using an optimization for simulation approach. This adds to the understanding of simulation estimate validity and uncertainty, which has been previously addressed in e.g. [21, 22]. The model is tested in a case study where the sea passage of the North Pacific Ocean for is replicated varying operational scenarios and seasons. Comparison is done towards equivalent simulation results performed without the sea passage model to evaluate its impact on propulsion power and fuel consumption estimates.

This paper is structured in seven sections. The following section addresses the combination of simulation and optimization and the potential added value for simulation-based design. Next, Sect. 3 presents the sea passage module, listing modelling assumptions and emphasise how the optimization routine is implemented into the simulation framework. Section 4 provides the case study particulars, with the corresponding case study results presented in Sect. 5. A thorough discussion on case study findings and sea passage model applicability and importance is given in 6. Finally, conclusions are given in Sect. 7.

\section{Simulation and optimization in simulation-based design}

This section discusses challenges associated with simulation-based design of ships and maritime systems and elaborates on the presented model logic using optimization for simulation.

\subsection{Virtual testing of concepts in operational conditions}

Simulating a ship in a seaway follows a comprehensive development and modelling effort. Models representing the ship and systems must be created at a fidelity level sufficient for representation of the real system. A metocean model or datasets for the areas of operation is needed to include the characteristics of environmental loads and corresponding variability in ship system performance.

Given that all models mentioned above are available to us, the next task is to utilise them in a manner that provides insight into the performance of the system. How to set up a simulation that provides relevant and meaningful results? In the present work, commercial ships during sea passage, with focus on application in simulation-based design is addressed following the scheme illustrated in Fig. 1. Simulation is in this context applied as a tool for converting synthesis (form) to semantics (function), i.e. answering questions about a particular design's performance in a specific scenario. 


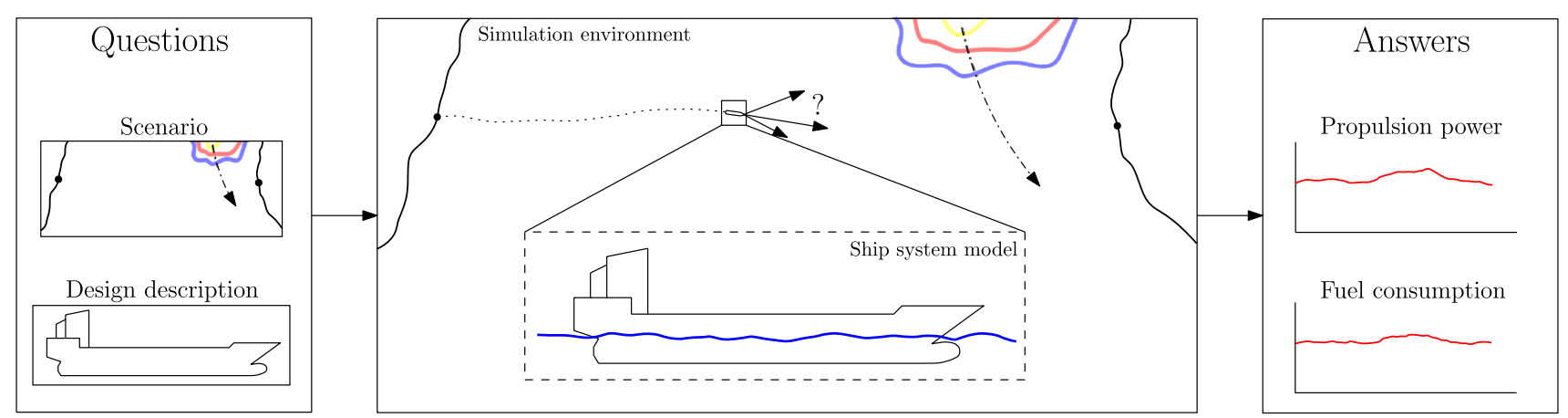

Fig. 1 Simulation as a tool for answering ship design questions

As mentioned in the introduction, scenarios can be created based on historical ship voyage data, e.g. AIS. Following this approach, route and target speed/power/RPM can be provided as part of the input to the simulator. This implies scenario relevance with reference to the full-scale data of the actual operation. However, historic data rarely contain information describing the operational constraints and the corresponding strain exerted on the system to meet them. Thus, one is often forced to assume that a given set of voyages is relevant for testing new technology without considering the operational measures which might be taken to facilitate integration of new systems. Reversed, if a system is found to limit operational capabilities, a fixed route and target speed approach limits the ability to establish the operational level of which a given system is sufficient.

The wave climate experienced by a vessel is affected by the operational pattern of which it operates, i.e. the ocean areas between visited ports. In addition, re-evaluation of plans for route and speed to avoid harsh weather conditions during passage affects the experienced weather for each individual voyage. The concern is that the consequence of ignoring or underestimating the importance of route and speed decisions during the voyage can cause an erroneous understanding of the required power and energy consumption of ship propulsion systems. This is illustrated in Fig. 1, where the sea passage decisions is part of the simulation link between questions and obtained answers.

\subsection{Optimization for simulation}

The term "required propulsion power" can be defined as the power necessary for a ship to maintain a certain speed. To provide a complete definition, a required speed must therefore be given. Further, deciding which speed is required in a given sea state is not straight forward. It will however have a significant effect on required propulsion power and consequently fuel consumption. To find an answer, one must consider the vessel's operating context. For example, there are scenarios in shipping where ship masters must decide whether or not to enter an area in which the weather forecast is rough. This is illustrated in Fig. 1 where a weather system approaching the vessel's path from the north is likely to interfere with the original schedule and time budget. In this case, one must decide whether passing through the weather system is "required", and if so, at what speed. Open ocean areas do however permit deviation from the initial route, which combined with speed variations must be evaluated. An optimization problem is therefore formed where possible route and speed alternatives are established and evaluated for the future voyage based on a set objective.

Figure 2 shows the principle idea for the model presented in this paper. With a complete model in the physical domain, the model is expanded into the operational domain to form a basis for the speed and route commands based on operational considerations. The captain controls the vessel by giving a series of throttle and rudder commands determined in general by the ship destination, occurring weather conditions and experience. Hence, the captain represents an interface between the physical and operational domain, converting mission constraints given by the ship owner to ship handling commands at sea. This functionality is what is replicated in the model in the present work. It may therefore be understood as an "artificial captain", providing ship handling commands in the model. This model also help bridge the gap between physical simulations and operations research by providing an interface between the physical and operational domain.

\section{Methodology}

This section presents the sea passage model scenario generation procedure. First, an introduction to the implementation in the simulator is given. Next, the sea passage model is presented in detail showing the sequential procedure of candidate route and speed generation and evaluation. Finally, the optimization steps and their relation is given in detail. 


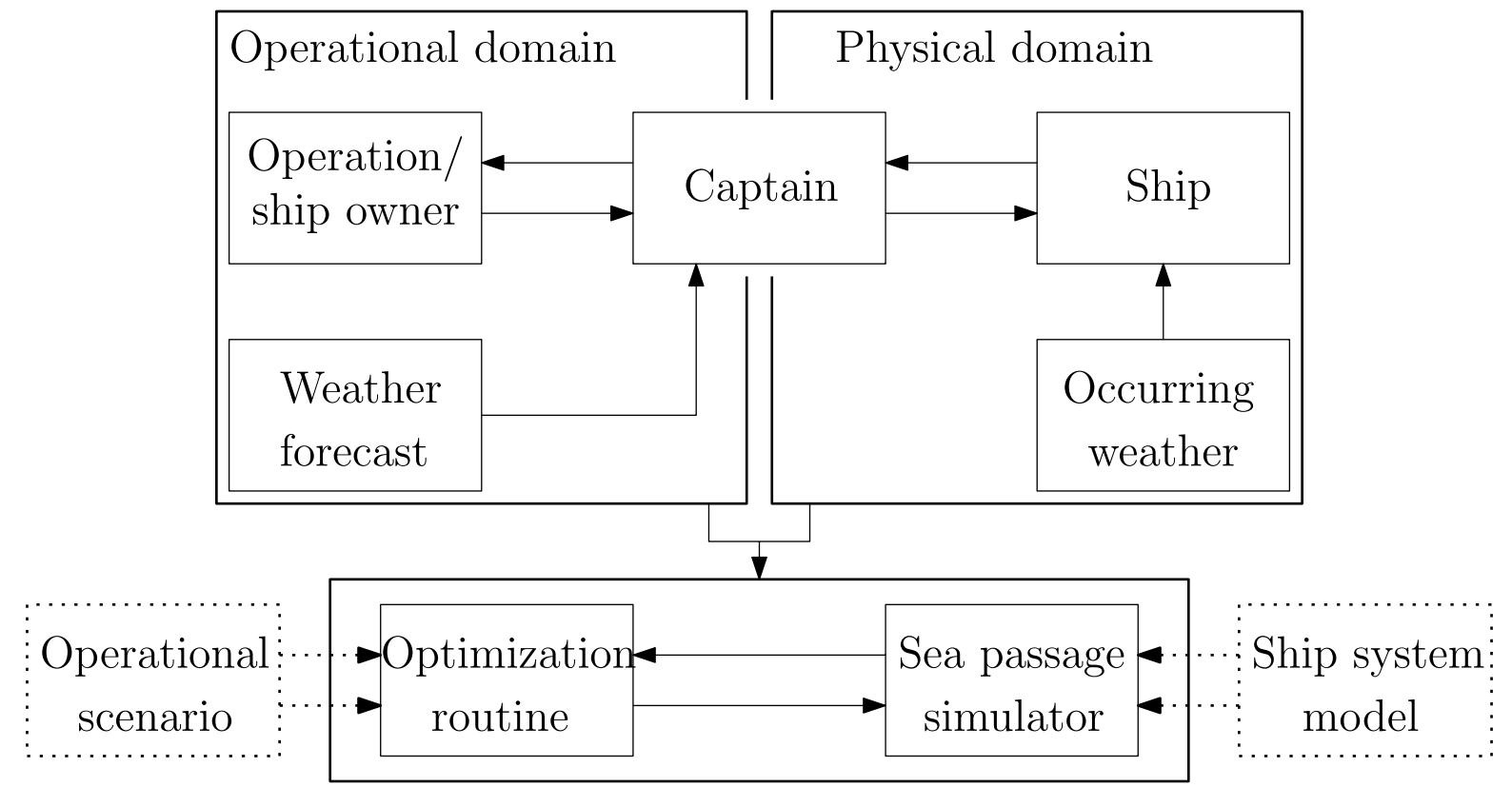

Fig. 2 Vessel captain as the interface between the operational and physical domain and application of optimization for simulation to generate operational scenarios

\subsection{Simulation route and speed management}

Figure 3 illustrates the logic implemented in the sea passage model. At the port of origin, the schedule is established assuming that the voyage will follow the great circle route and a given target speed. The model initialises the voyage by determining an initial heading and speed. It is assumed that a reliable weather forecast is available for the next $h$ hours, which combined with a statistical estimate for the vessel's fuel consumption for $t>h$ are used as a basis for the decision. Further, it is assumed that the criteria relevant for the voyage are the fuel consumption and delay penalties set by the stakeholders.

After departure the vessel maintains a constant heading and target speed for $u_{\mathrm{p}}$ hours at which the route and speed is re-evaluated. The progress of the vessel is affected by the occurring sea states, which may cause voluntary and involuntary speed-losses depending on the rated power and captain's ship handling procedure.

\subsubsection{Sea passage model}

Figure 4 shows the sequential sea passage model algorithm. From the simulator, the sea passage model is given the current location and time as input. The algorithm then follows five major steps for evaluating the current weather situation and providing the recommended heading and speed to the simulator:

1. Candidate route generation $R_{\psi \mathrm{v}_{h} \mathrm{st}}$

From the current vessel location, the shortest route, i.e. great circle route, to the port of destination is cal-

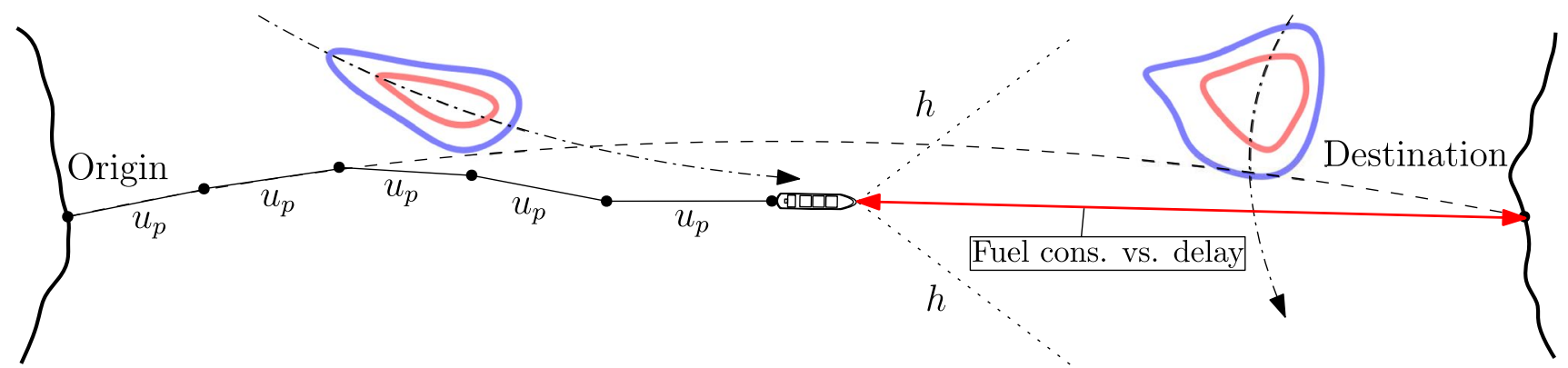

Fig. 3 Simulation route and speed management 


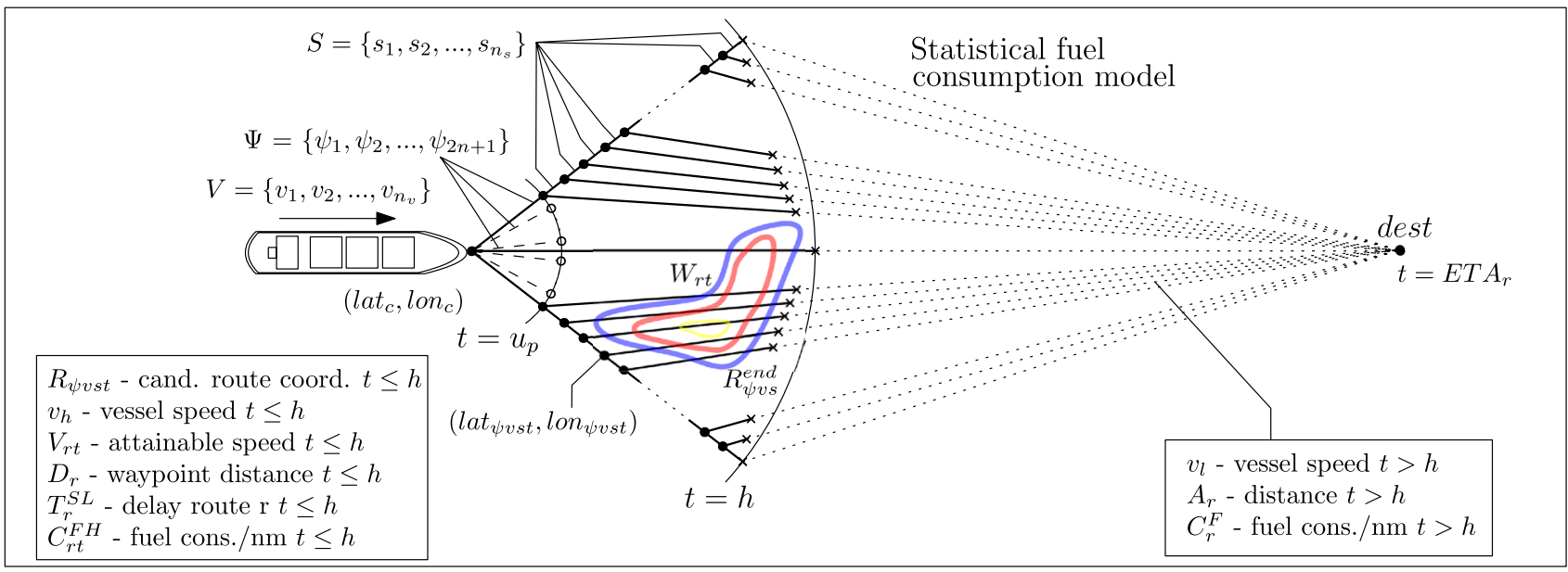

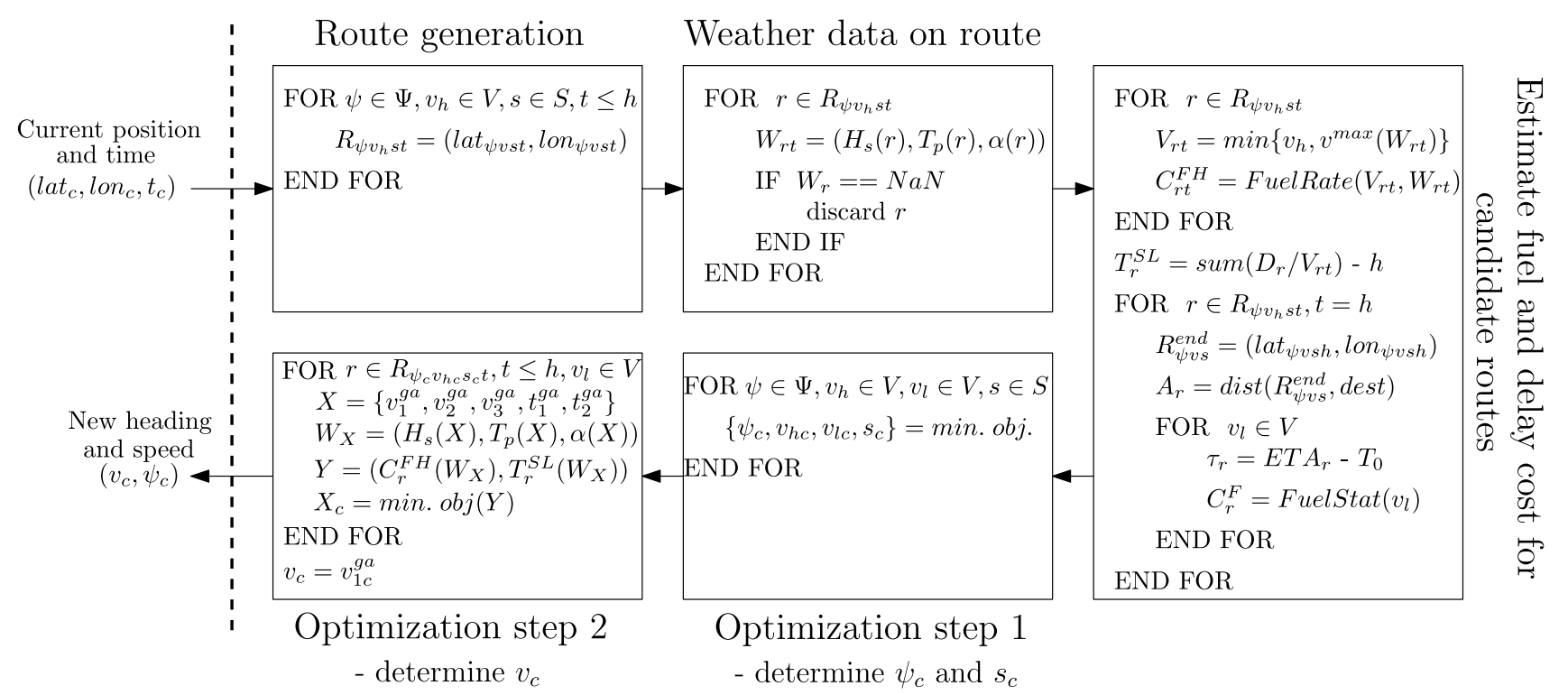

Fig. 4 Sea passage model pseudocode and overview of important variables and parameters

culated. To each side of the shortest route, $n$ candidate headings are defined with spacing $\Psi_{\text {max }} / n$, where $\Psi_{\text {max }}$ is the maximum shortest route offset angle. The simulation updates route and speed at regular intervals with update period $u_{\mathrm{p}}$, so the first leg of each candidate heading is assumed to follow the great circle route from the current position with each candidate heading as initial heading. Beyond time horizon $u_{\mathrm{p}}$, a great circle route is generated for each candidate heading for a duration of $h-u_{\mathrm{p}}$ hours, where $h$ is the horizon reliable weather forecasts is available. This route segment is further divided in $n_{\mathrm{s}}$ segments $S$ of equal distance. For each segment, a great circle route is generated towards the port of destination. The length of each segment is calculated so that the total sailing time for all routes in $R_{\psi \mathrm{v}_{h} \mathrm{st}}$ is $h$ hours. The great circle route between the current position and destination is not subject to further decomposition, see Fig. 4. Since the route generation procedure is isochrone based, the set of candidate routes is vessel speed dependent. A set of candidate speeds $v_{h} \in V$ is therefore defined.

2. Retrieve weather data $W_{\text {rt }}$

Wave hindcast datasets are used to replicate the conditions encountered along the route. The data is stored in a grid format, indexed by latitude, longitude and time. Significant wave height $\left(H_{\mathrm{s}}\right)$, spectral peak period $\left(T_{\mathrm{p}}\right)$ and wave propagation direction $(\alpha)$ are gathered in $W_{\mathrm{rt}}$ for each candidate route waypoint using route coordinates and point arrival times calculated based on vessel speed. Spatial and temporal interpolation is used to produce wave data estimates. NaN values present in the dataset indicate land, so a check is made whether any of the routes in $R_{\psi v_{h} s t}$ crosses land areas. Routes crossing land are discarded for further evaluation.

3. Fuel consumption $\left(C_{r t}^{F H}, C_{r}^{F}\right)$ and delay $\tau_{r}$ estimation 
Fuel consumption rate $\left(C_{r t}^{F H}\right.$ is calculated for each route leg $r \in R_{\psi v_{h} s t}$ considering the forecast waves $W_{r t}$ and vessel speed $V_{r t}$ for $t \leq h$. These estimates are generated using a table look-up model (function FuelRate in Fig. 4), see Sect. 4.2. If $v_{h}$ requires more power than available, or ship handling concerns demand a speed reduction, $V_{r t}$ reduces accordingly. Each candidate route is initially scheduled to have a duration of $h$ hours. However, if $V_{r t}$ attains a reduced level the delay period $T_{r}^{S L}$ increases.

From the end of each candidate route $R_{\psi v s}^{\text {end }}$, a great circle route is calculated to the destination with distance $A_{r}$ (function dist in Fig. 4). Fuel consumption rate $C_{r}^{F}$ along this route is based on a statistical model (function FuelStat in Fig. 4) as a function of vessel average speed $v_{l}$, see Sect. 4.4. The model allows $v_{h} \neq v_{l}$ so that different trade-offs between fuel consumption and delay can be assessed. ETA $A_{r}$ is calculated considering $v_{h}, v_{l}$ and speed loss, shown in Eq. 2.

4. Route and speed decision $\left(v_{c}, \psi_{c}\right)$

The route and speed optimization is done in two steps discussed in further detail in Sect. 3.1.2:

(a) Optimum route $R_{\psi_{c} v_{h c} v_{l c} s_{c} t}$ determined assuming constant speed $v_{h c}$ for $t \leq h$. Output value for new heading $\psi_{c}$ is determined.

(b) A speed profile is fitted for route $R_{\psi_{c} v_{h c} v_{l} s_{c} s_{c}}$ using a genetic algorithm. In the pseudocode in Fig. 4, $X$ is a candidate set of speed profile variables, from which weather along the route $W_{X}$ is obtained. Fuel consumption $C_{r t}^{F H}$ and delay period $T_{r}^{S L}$ is updated accordingly and stored in $Y$, which is used to evaluate the objective function. Output value for new speed $v_{c}$ is determined.

\subsubsection{Optimization procedure}

The mathematical formulation for the decision making process is expressed in the objective function stated in Eq. 1. As mentioned, the sea passage behaviour is controlled by two input variables; the target speed and delay cost. During simulation initiation, a target time of arrival $T_{0}$ is calculated based on the target speed and the shortest sailing distance between port of departure and port of destination, i.e. the great circle route. The sea passage model attempts to complete the sea passage using a minimum amount of fuel. However, it also has a motivation to complete the passage within the target time, modelled using a linearly increasing delay cost with rate $\kappa$.

The objective function, minimising fuel consumption for the remaining voyage and delay costs, is expressed as $\min \sum_{r \in R_{\psi v} v_{h l s}} \sum_{t \leq h}\left(C_{r t}^{\mathrm{FH}} D_{r}+C_{r}^{F} A_{r}+\kappa \tau_{r}\right) x_{r}$

Each route is associated with a speed $v_{h}$ which determines the distance covered on time interval $t \leq h$ for which the wave conditions are assumed known and fuel cost rate $C_{r t}^{F H}$ and speed loss delay $T_{r}^{S L}$ are calculated accordingly. $x_{r}$ is a binary variable equal to 1 if the speed $v_{h}$ is chosen for the first $h$ hours, $v_{l}$ for the remaining time until destination, current heading $\psi$ and route extension interval $S$ is chosen, 0 otherwise. $D_{r}$ is the waypoint distance and $A_{r}$ is the distance from the end of the observable horizon to the voyage destination, as defined in Sect. 3.1.1. $\tau_{r}$ is the estimated delay time, which is expressed

$\tau_{\mathrm{r}}=t_{\mathrm{c}}+h+\frac{A_{r}}{v_{l}}+T_{\mathrm{r}}^{\mathrm{SL}}-T_{0}$,

where $t_{\mathrm{c}}$ is the current simulation time, $T_{\mathrm{r}}^{\mathrm{SL}}$ is the estimated speed loss delay within the observable horizon $h$. The route generation procedure and objective function in Eq. 1 assume a constant vessel speed throughout the horizon. However, depending on the variation of sea state severity over the horizon, a constant speed assumption may not be a realistic representation. Given for instance that the operation has a strict delivery deadline, and encountering stormy conditions is unavoidable, it may be beneficial to speed up in calmer sea state periods. To model a varying speed planning strategy, a speed profile for the observable weather horizon is formulated, see Fig. 5. The speed profile consists of three time periods of constant speed, described by three speed level variables $\left\{v_{1}^{g a}, v_{2}^{g a}, v_{3}^{g a}\right\}$ and two speed adjustment time variables $\left\{t_{1}^{g a}, t_{2}^{g a}\right\}$. Searching for the optimal speed profile is done using a genetic algorithm heuristic, which evaluates the objective function in Eq. 1 considering changes in encountered wave conditions along the route in the observable time horizon. Estimates of voyage fuel consumption and delay costs are calculated accordingly. Hence, the optimization procedure is divided in two steps as illustrated in Figs. 4 and 5.

\section{Case study}

A comprehensive case study has been performed to investigate the model sensitivity towards parameters and input variables. This section presents the case study particulars and assumptions. First, the sea passage model parameters and assumptions for each scenario is given. Next, the ship system model and speed loss assumptions are given. Finally, the statistical model applied for the final leg of the voyage is presented. 


\subsection{Scenarios and sea passage model parameters}

Sea passage over the North Pacific is simulated in all scenarios. More specifically, the vessel starts the voyage outside Tokyo at coordinates $35^{\circ} 43^{\prime} \mathrm{N}, 141^{\circ} 4^{\prime} \mathrm{E}$ and crosses the North Pacific eastbound towards San Francisco at $37^{\circ} 40^{\prime} \mathrm{N}$, $236^{\circ} 31^{\prime}$ E. Hindcast wave data for this area is collected from the European Centre for Medium-Range Weather Forecasts ERA-5 catalogue [23]. Simulations are stopped when the distance to the destination in San Francisco is lower than $u_{\mathrm{p}} \cdot V_{\max }$, i.e. 102 nautical miles. Table 1 lists sea passage model parameters the case study. Vessel speed is assumed to vary on the interval between 10 and 17 knots with spacing one knot. This level of discretization was chosen partly to reduce the number of route evaluations in the sea passage model, thus decreasing the computational effort. Further, a fine discretization of vessel speed is likely to cause small and frequent speed level transitions in the mathematical model, which is considered unlikely for an oil tanker. Route generation is done with a maximum offset angle $\Psi_{\max }$ relative to the heading from the current location to destination following the great circle route. The spacing between headings $n$ and route segments $n_{\mathrm{s}}$ on the time interval $h-u_{\mathrm{p}}$ (see Fig. 4) is assumed equal and subject for a convergence study in Sect. 5.1. The optimization routine is initiated every $u_{\mathrm{p}}$ hours, providing new throttle and heading commands. It is assumed in this study that reliable weather forecast is available for the subsequent $h$ hours, which is discussed in Sect. 6.2. Leaving the port of origin, the target time is calculated based on the shortest distance to destination (4268 nautical miles) and target speed 14 knots. Hence, arrival at time $t>T_{0}=304.8 \mathrm{~h}$ will introduce delay costs with rate $\kappa$ in the model.

To test the impact of the sea passage model on required power and fuel consumption estimates, five scenarios are established as shown in Table 2. Each scenario affects the
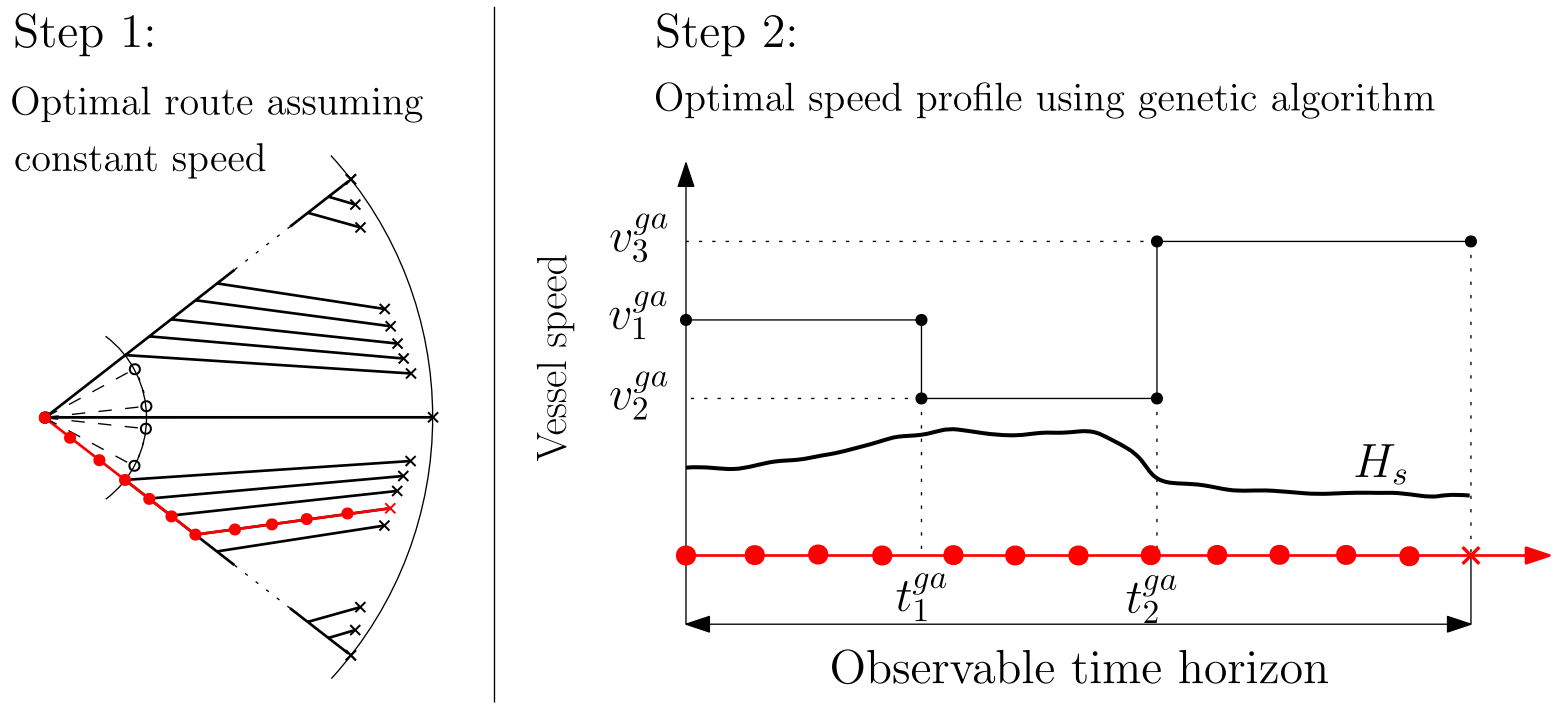

Fig. 5 Optimization procedure divided in two steps for providing heading and speed input for the simulator

Table 1 Case study sea passage model parameters

Table 2 Sea passage scenarios

\begin{tabular}{|c|c|c|c|c|c|c|}
\hline Parameter & $\begin{array}{l}V \\
{[\mathrm{kn}]}\end{array}$ & $\begin{array}{l}\Psi_{\max } \\
\text { [deg.] }\end{array}$ & $\begin{array}{l}n=n_{\mathrm{s}} \\
{[-]}\end{array}$ & $\begin{array}{l}u_{\mathrm{p}} \\
{[\mathrm{h}]}\end{array}$ & $\begin{array}{l}h \\
{[\mathrm{~h}]}\end{array}$ & $\begin{array}{l}\text { Dist. g.c. } \\
{[\mathrm{nm}]}\end{array}$ \\
\hline Value & $10: 1: 17$ & \pm 45 & 10 & 6 & 72 & 4268 \\
\hline
\end{tabular}

\begin{tabular}{|c|c|}
\hline Scenario & Description \\
\hline $\mathrm{V} 14 \kappa 4$ & Sea passage model with delay cost $\kappa=4$ tons/hour. Target speed 14 knots \\
\hline $\mathrm{V} 14 \kappa 7$ & Sea passage model with delay cost $\kappa=7$ tons/hour. Target speed 14 knots \\
\hline $\mathrm{V} 15 \kappa 10$ & Sea passage model with delay $\operatorname{cost} \kappa=10$ tons/hour. Target speed 15 knots \\
\hline Fixed14 & Great circle route between origin and destination. Fixed speed 14 knots \\
\hline Fixed15 & Great circle route between origin and destination. Fixed speed 15 knots \\
\hline
\end{tabular}


vessel's route and speed decisions by changing the tolerance for deviating from the initial plan. Fixed14 and Fixed15 represents scenarios where the ship behaviour is assessed without access to the sea passage model. The speed policy for Fixed 14 and Fixed 15 is to maintain a constant speed of 14 and 15 knots except for sea states where voluntary and involuntary speed loss occur, see Sect. 4.3.

Figure 6 shows the statistical cost estimates for each scenario in Table 2 based on the statistical model presented in Sect. 4.4. Scenario V14 $\kappa 4$ costs have a close to flat interval for approximately $24 \mathrm{~h}$ after the planned voyage completion time which facilitate route deviations and speed adjustments. $\mathrm{V} 14 \kappa 7$ has the same planned voyage completion time as $\mathrm{V} 14 \kappa 4$, but a higher delay cost which replicates a stricter delivery deadline. To test the capabilities of the vessel, the final scenario $\mathrm{V} 15 \kappa 10$ replicates a more urgent delivery which will require higher levels of propulsion power to succeed.

\subsection{Ship system simulation model}

The KVLCC 2 is taken as the case vessel in the present work. This vessel was chosen because it has been extensively modelled and studied in previous work, which has been available to the authors in the present studies. Hence, the sea passage model presented in this paper is an effort for further development and improvement of previous modelling and research efforts.
This case study utilise a time domain model of the KVLCC2 consisting of a two-stroke diesel engine model, a propeller model and a ship hull model created and documented by Taskar et al. [24], Yum et al. [25]. A detailed explanation of the model can be found in Taskar et al. [24]. The simulations in the present work is performed using a discrete-event framework developed in MATLAB. A table look-up dataset is created by simulating combinations of sea states, wave directions and vessel speeds in the time domain model. Each combination is simulated until steady state is reached.

The simulator uses quasi-static wave added resistance estimates obtained using the extended Gerritsma and BeukeIman model derived by Loukakis and Sclavounos [26]. Stern and stern-quartering wave added resistance estimates for this method contain uncertainties, and analysis of KVLCC2 show significant negative amplitudes for this encounter angle range. Park et al. [27] compare added resistance estimates for oblique waves using two numerical methods and experimental tests for the S-VLCC, which has similar dimensions and hull shape as the KVLCC2. Added resistance is found to decrease gradually from bow-quartering $\left(120^{\circ}\right.$ angle of attack) to following seas, with little or no added resistance from following seas. They also show that the added resistance estimates are overestimated by the strip theory method for head sea conditions compared to experiments and the 3D Rankine panel method, which should be kept in mind for the present study. Valanto and Hong [28] investigate the added resistance in oblique waves for a cruise ship, and
Fig. 6 Scenarios and statistical cost model

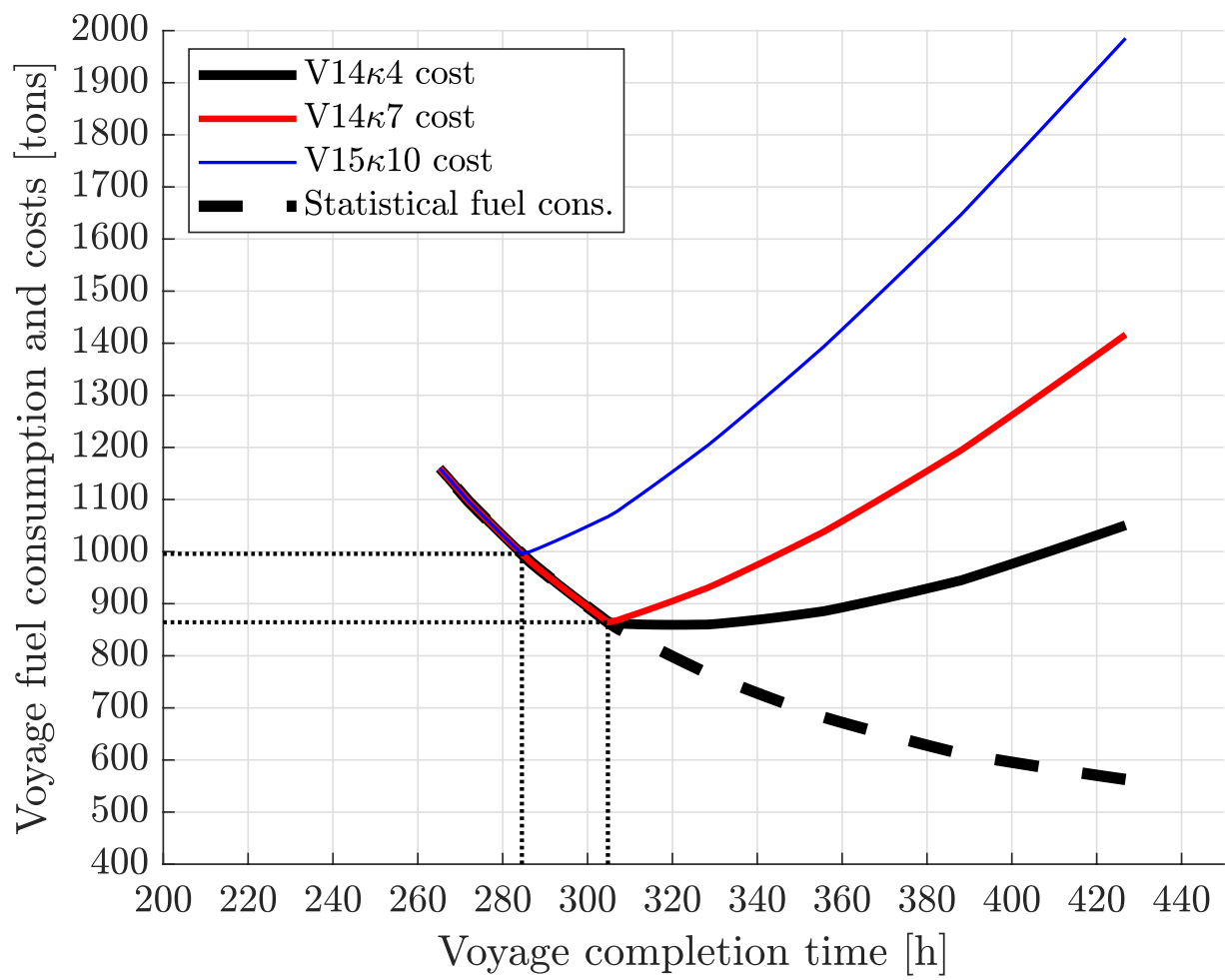


Liu and Papanikolaou [29] for a bulk carrier and Duisburg Test Case (DTC) ship, using experiments and show small negative added resistance coefficients for short following waves. However, wave amplitude is limited in this region due to wave breaking, and the effect on an oil tanker is likely negligible. It is therefore assumed no positive propulsion contribution from the waves, i.e. negative added resistance coefficients are discarded and assumed zero.

\subsection{Speed losses}

Speed-losses occur as a consequence of insufficient propulsion power or voluntary actions by the captain to prevent excessive motions and loads. Voluntary speed loss is modelled using the criteria listed in Table 3 calculated using short-term statistics in the frequency domain. The criteria is adopted and modified from [30]. KVLCC2 has a design draft of $20.8 \mathrm{~m}$ making propeller emergence and bow slamming unlikely for normal wave conditions. The deck wetness criterion is found to be the limiting criterion for close to all sea state and speed combinations.

The maximum power output for the engine is set to $100 \%$ maximum continuous rating (MCR). The vessel time domain model engine governor is set to accept speed loss if required power exceeds this level. Further, propeller emergence will also cause speed loss as outlined in [31].

\subsection{Statistical sea passage model for final $\operatorname{leg} t>\boldsymbol{n}$}

For $t>h$ it is assumed that weather forecasts is unavailable, but an estimate for fuel and delay costs are needed for the remaining part of the voyage in the sea passage model. This is done using a statistical model. To obtain estimates regarding fuel consumption and delay, estimates are needed for the available average speed $\bar{V}_{\text {att }}$ based on the attainable speed $V_{\text {req }}\left(h_{s}, t_{p}\right)$ for the vessel in waves and occurrence probabilities for each sea state $p\left(h_{s}, t_{p}\right)$. DNV GL [32] lists parameters for the joint distribution $f_{H_{s} T_{p}}\left(h_{s}, t_{p}\right)$ for world wide trade in Appendix C Table C-5 which is applied for the sea state occurrence probabilities. For this model it is assumed head waves only. The table look-up model is generated for a set of sea states $\left(h_{s}, t_{p}\right) \in \Gamma$, from which the attainable speed due to involuntary speed loss $V_{\text {req }}^{i s l}\left(h_{s}, t_{p}\right)$ is obtained by com-

Table 3 Voluntary speed loss criteria

\begin{tabular}{llll}
\hline Criterion & Probability & Limit & Location \\
\hline Slamming & $2.0 \%$ & - & Bow \\
Vert. acc. & - & 0.215 g RMS & Bow \\
Deck wetness & $1.0 \%$ & - & Stern-midship-bow \\
Prop. emergence & $0.2 \%$ & - & Propeller \\
\hline
\end{tabular}

paring requested speed and steady-state speed in the time domain model. Attainable speed due to voluntary speed $V_{\text {req }}^{v s l}\left(h_{s}, t_{p}\right)$ loss is included following the criteria in Table 3. The attainable speed is then calculated as

$V_{\text {req }}\left(h_{\mathrm{s}}, t_{\mathrm{p}}\right)=\min \left\{V_{\text {req }}, V_{\text {req }}^{i s l}\left(h_{\mathrm{s}}, t_{\mathrm{p}}\right), V_{\text {req }}^{v s l}\left(h_{\mathrm{s}}, t_{\mathrm{p}}\right)\right\}$

where $V_{\text {req }} \in V$ is a constant requested speed. In the analysis, a constant speed policy is assumed where the vessel maintains speed $V_{\text {req }}$ as long as no speed loss criterion reduces it according to Eq. 3. The occurrence of speed reduction sea states is governed by $p\left(h_{\mathrm{s}}, t_{\mathrm{p}}\right)$, enabling us to compute the expected attained average speed $\bar{V}_{\text {att }}$ as

$\bar{V}_{\text {att }}\left(V_{\text {req }}\right)=\sum_{\left(h_{s}, t_{p}\right) \in \Gamma} p\left(h_{s}, t_{p}\right) \cdot V_{\text {req }}\left(h_{s}, t_{p}\right)$

and the weighted average fuel consumption

$\bar{f}_{\mathrm{c}}\left(V_{\text {req }}\right)=\sum_{\left(h_{s}, t_{p}\right) \in \Gamma} p\left(h_{s}, t_{p}\right) \cdot f_{\mathrm{c}}\left(V_{\text {req }}, h_{s}, t_{p}\right)$,

where $\bar{f}_{\mathrm{c}}$ and $f_{\mathrm{c}}$ are the weighted average and table look-up fuel consumption, respectively. Figure 7 shows the statistical model and illustrates its application in the sea passage model. To obtain an average speed $\bar{V}_{\text {att }}$, the requested sailing speed according to a constant speed sailing policy is $V_{\text {req }}$, which is taken as the basis for the fuel consumption calculation for the remaining distance. Hence, the ability to actively adjust speed and route for the remaining sailing distance $t>h$ is not considered.

\section{Results}

This section presents the results from the case study outlined in Sect. 4. First, the results from the convergence study performed to determine $n$ and $n_{\mathrm{s}}$ is presented. Next, the resulting routes from the sea passage model are shown followed by wave environment statistics. Then the fuel consumption and propulsion power estimates are given before results highlighting the effect storm avoidance and speed management in the sea passage model is presented.

\subsection{Candidate route generation study}

The sea passage model's perception of the wave environment surrounding the vessel is highly dependent on the candidate route generation procedure. In addition, the level of choices available for the model must be sufficiently high. To investigate the dependency towards candidate route generation input, a case study with varying $n$ and $n_{\mathrm{s}}$ was conducted, see Fig. 4 . In the study cases assuming $n_{\mathrm{s}}=n$ were simulated, and increased $n$ on the interval from 1 to 15 . 


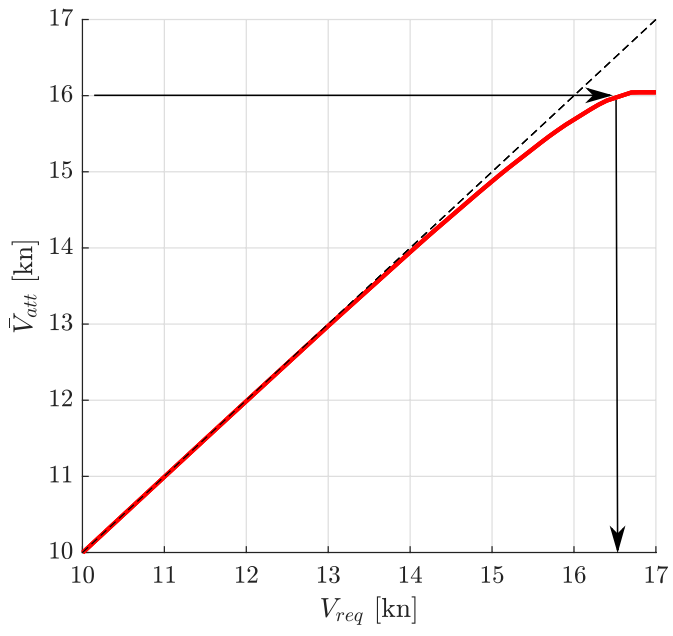

Fig. 7 Statistical average speed and fuel consumption model

Figure 8 shows the simulated routes from the sea passage model for each parameter $n$ and the resulting observed significant wave height $\left(H_{\mathrm{s}}\right)$ spectral peak period $\left(T_{\mathrm{p}}\right)$ time series. It is clear that only including a low number of heading alternatives, shown using red lines, has a significant effect on the resulting route. This affects the encountered sea state conditions along the route. For high $n$, i.e. 10, 12 and 15, the routes and encountered wave conditions coincide well.

Figure 9 shows the obtained headings relative to the great circle route heading towards destination and planned periods for constant heading for each decision along the routes in Fig. 8. For $n=1$, the available headings in the model are very limited, i.e. $+45,0$ and 45 degrees only. This causes the model to only deviate from the great circle heading on four occasions. In contrast, the remaining routes are sailed with an offset to the destination great circle route for the majority of the time. Initially, all cases follows a heading north of the great circle heading, i.e. port on the eastbound voyage. Following decision number 13 (i.e. $t=78 \mathrm{~h}$ ), the model shifts

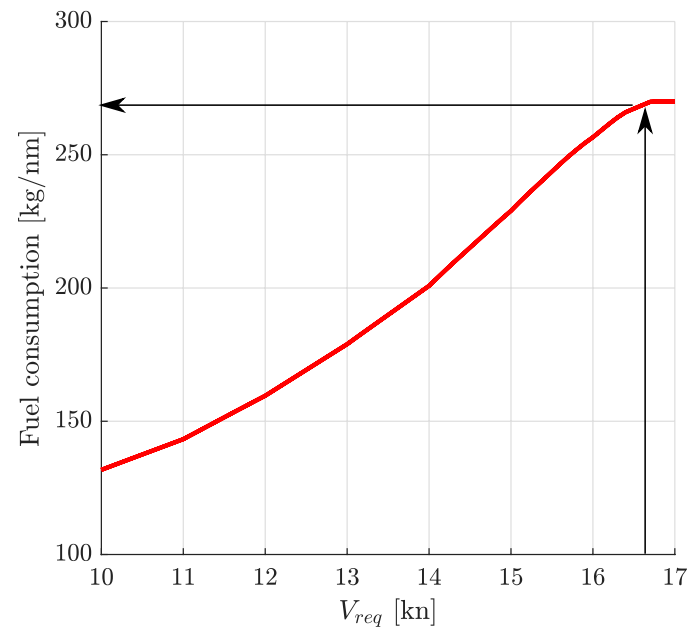

heading frequently between port and starboard of the great circle heading. However, all cases follow the same overall pattern. This means that all routes follow the same mode in terms of how storms are encountered, but with a varying ability to manoeuvre around them. The plot showing the planned period for constant heading in Fig. 9 illustrates the impact of varying $n_{\mathrm{s}}$, as seen in Fig. 4. As for the heading, a similar overall pattern for how the model plans to conduct the sea passage is observed.

Figures 8 and 9 show that convergence is obtained for $n=$ 10 , with little changes in sea passage characteristics beyond this level. Hence, $n=10$ is applied for the remaining case studies.

\subsection{Sea passage routes}

Figure 10 shows the resulting routes of the sea passage model and great circle route applied in scenarios Fixed14 and Fixed15. The level of deviation from the great circle
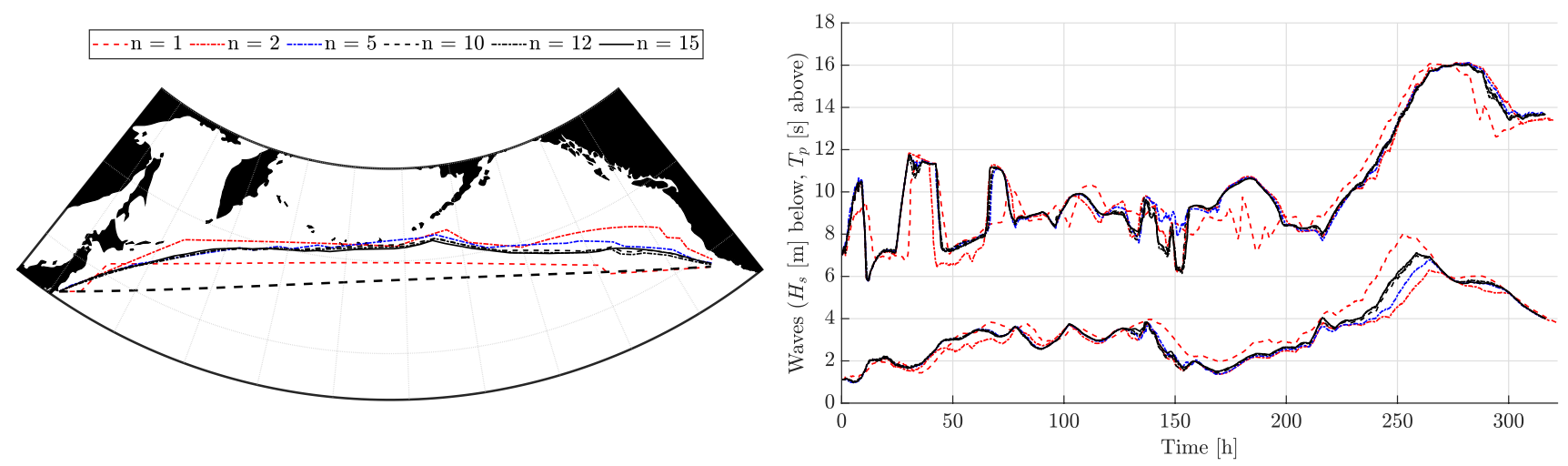

Fig. 8 Resulting vessel routes for different route generation parameters. Thick black dashed line indicating great circle route between origin and destination 

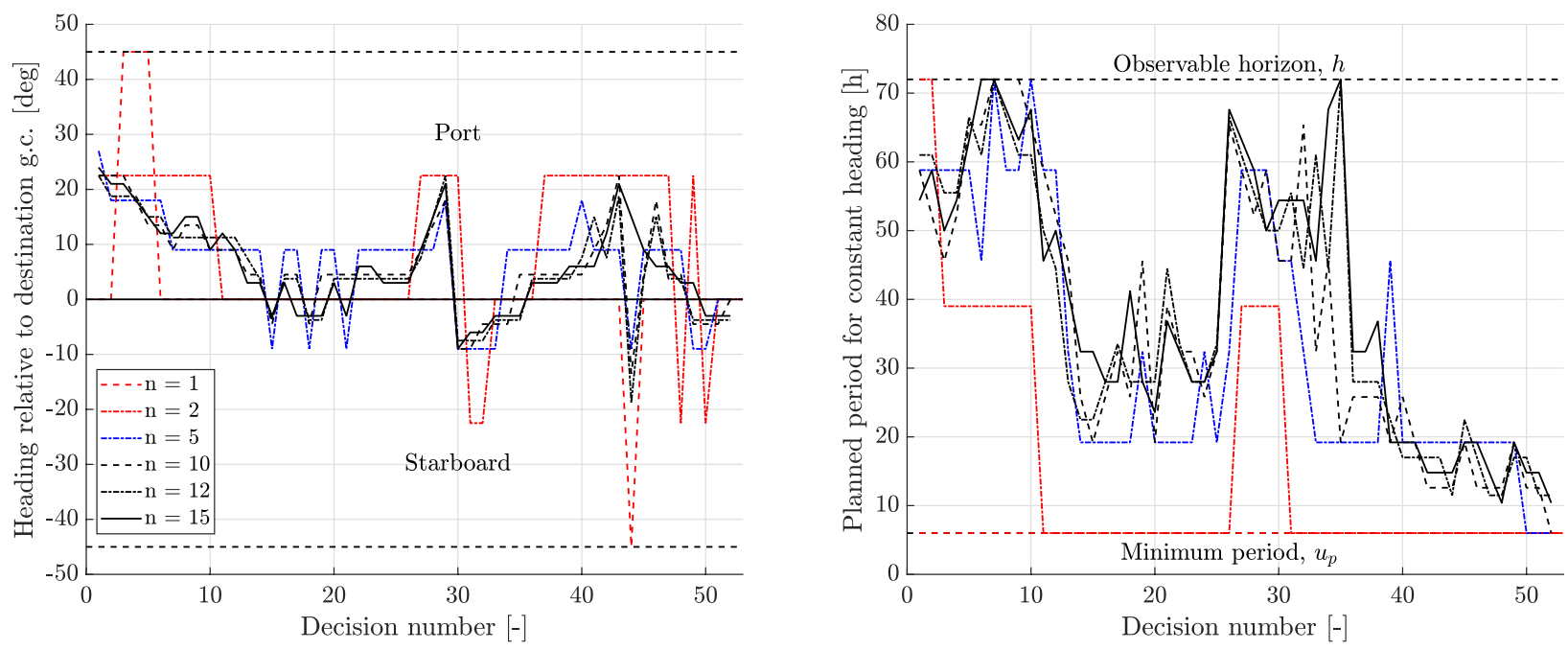

Fig. 9 Vessel headings (left) and planned period for constant heading (right) for different route generation parameters

route is found to vary significantly depending on delay cost and season. In general, high delay cost causes the model to follow a route closer to the great circle, minimising the required sailing distance. Each season represents a different weather scenario the model must navigate through. For the months February, March, April, August, October and November large deviations are observed from the great circle route caused by harsh sea states.

Table 4 lists the resulting sea passage scenario characteristics. The late arrival costs have a clear effect on sailed distance and average speed. Cases with large sailed distances indicate that the sea passage model has taken evasive action in the presence of storms, resulting in a longer route than originally planned. The optimization model must in these scenarios decide whether to increase the planned arrival time or sailing speed, which will depend on the estimated fuel and delay costs. The average speed results indicate that varying the delay cost is an effective method for shifting this threshold.

\subsection{Power and fuel consumption}

Tables 5 and 6 list the propulsion power and fuel consumption estimates for each simulated scenario, respectively. The required propulsion power varies greatly from month to month, with the summer months resulting in the lowest levels. The impact of the scenario assumptions is also found to be season dependent. For seasons with calm conditions, little or no difference in required propulsion power and fuel consumption is found. However, significant differences are found for the harsher seasons. January-April and October-November produce high levels of required propulsion power and fuel consumption in all scenarios, although with large differences for each individual scenario.
Figure 11 shows a scatter plot of the voyage completion time and fuel consumption in Tables 4 and 6 for the sea passage model scenarios and fixed simulations with the statistical model described in Sect. 4.4. Dotted lines indicate the statistical estimate for the required fuel consumption assuming an average speed of 14 and 15 knots along the great circle route. Figure 6 shows that the V $14 \kappa 4$ scenario has slack in arrival time impact on total costs, which results in a wide distribution of simulated voyage completion times. V14 7 does not have the same level of slack, which causes the simulator to ensure arrival closer to target. This behaviour does however result in a wider distribution of estimated fuel consumption. The same scatter pattern is found for the $\mathrm{V} 15 \kappa 10$ scenario for a shorter completion time. The Fixed14 and Fixed15 scenarios arrive according to plan in the calm months, but have significant delays due to speed loss in harsh weather months. The fuel consumption is found to be significantly higher for Fixed 14 compared to V $14 \kappa 7$ for approximately the same arrival time in the harsh weather months. The same is found by comparing Fixed 15 and V15K 10.

\subsection{Wave environment}

Table 7 shows the mean encountered $H_{\mathrm{s}}$ for each simulated scenario. For the seasons with low mean, only small differences are observed between the scenarios. However, for some of the rougher seasons, significant differences are observed, e.g. March, April and October. Figure 10 shows that these cases resulted in large deviations from the great circle route, which explains the differences in observed $H_{\mathrm{s}}$. The months with the harshest observed conditions are also found to give the largest route duration in Table 4 and fuel consumption in Table 6. 

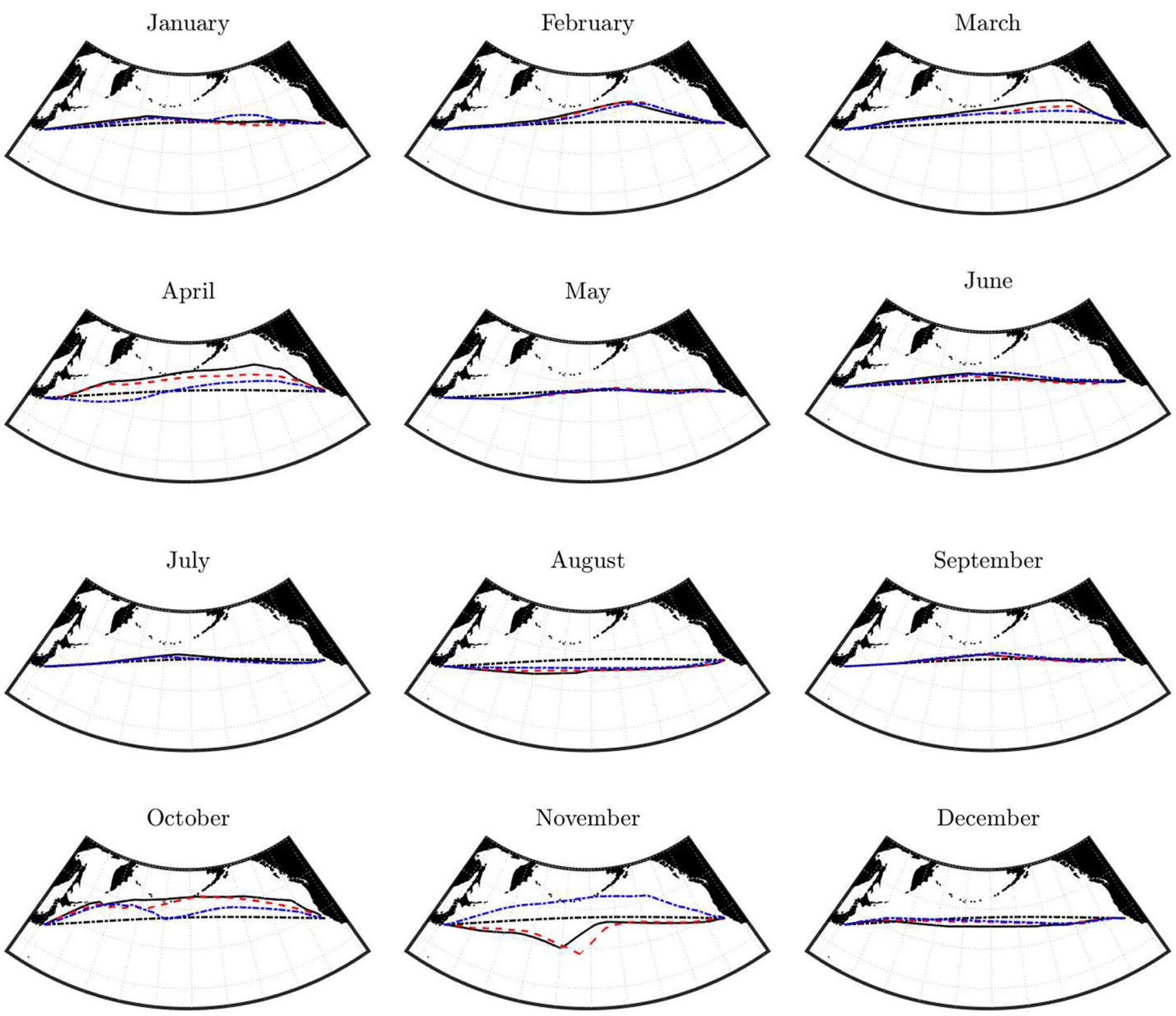

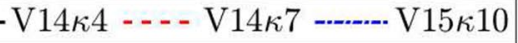

Fig. 10 Sea passage routes obtained using the sea passage model

Figure 12 shows the total wave scatter diagram for all months encountered in each simulated scenario. Note that Fixed 14 and Fixed 15 are plotted in the same plot as these scenarios represent the same weather routing assumption. The $\mathrm{V} 14 \kappa 4$ and $\mathrm{V} 14 \kappa 7$ simulations have avoided areas where the significant wave height exceeds $8 \mathrm{~m}$. V $15 \kappa 10$ and Fixed scenarios encounter waves exceeding $9.5 \mathrm{~m}$. The most frequent sea states are $H_{\mathrm{s}} 1.5-3 \mathrm{~m}$ and $T_{\mathrm{p}} 7-10 \mathrm{~s}$ in all scenarios. The sea passage model will attempt to reduce $H_{\mathrm{s}}$ as much as possible to minimize added resistance. However, the prevalence and persistence of these sea state conditions makes them the most frequently encountered sea states in all scenarios.

\subsection{Storm avoidance and speed management}

Table 7 shows that the observed weather conditions vary depending on season and simulation scenario. In Sect. 3, the sea passage module was presented and how it actively decides on the best route based on an optimisation algorithm taking the forecast weather into account was illustrated. Compared to the simulation scenarios with fixed route and speed, Tables 5 and 6 indicate that the sea passage module has a significant impact on the understanding of the required resources for crossing the North Pacific. These differences are however highly dependent on season, with only minor differences observed in the summer months. 
Table 4 Scenario result overview

\begin{tabular}{|c|c|c|c|c|c|c|c|c|c|}
\hline \multirow[t]{2}{*}{ Scenario } & \multicolumn{3}{|l|}{$\mathrm{V} 14 \kappa 4$} & \multicolumn{3}{|l|}{$\mathrm{V} 14 \kappa 7$} & \multicolumn{3}{|l|}{$\mathrm{V} 15 \kappa 10$} \\
\hline & $\begin{array}{l}\text { Distance } \\
{[\mathrm{nm}]}\end{array}$ & $\begin{array}{l}\text { Duration } \\
{[\mathrm{h}]}\end{array}$ & $\begin{array}{l}\text { Average } \\
\text { speed }[\mathrm{kn}]\end{array}$ & $\begin{array}{l}\text { Distance } \\
{[\mathrm{nm}]}\end{array}$ & $\begin{array}{l}\text { Duration } \\
{[\mathrm{h}]}\end{array}$ & $\begin{array}{l}\text { Average } \\
\text { speed }[\mathrm{kn}]\end{array}$ & $\begin{array}{l}\text { Distance } \\
{[\mathrm{nm}]}\end{array}$ & $\begin{array}{l}\text { Duration } \\
{[\mathrm{h}]}\end{array}$ & $\begin{array}{l}\text { Average } \\
\text { speed }[\mathrm{kn}]\end{array}$ \\
\hline January & 4290 & 330 & 13.0 & 4356 & 312 & 14.0 & 4314 & 300 & 14.4 \\
\hline February & 4374 & 336 & 13.0 & 4404 & 312 & 14.1 & 4404 & 300 & 14.7 \\
\hline March & 4374 & 324 & 13.5 & 4362 & 312 & 14.0 & 4348 & 294 & 14.8 \\
\hline April & 4458 & 348 & 12.8 & 4408 & 312 & 14.1 & 4365 & 300 & 14.5 \\
\hline May & 4368 & 324 & 13.5 & 4284 & 306 & 14.0 & 4332 & 288 & 15.0 \\
\hline June & 4362 & 318 & 13.7 & 4284 & 306 & 14.0 & 4314 & 288 & 15.0 \\
\hline July & 4314 & 312 & 13.8 & 4290 & 306 & 14.0 & 4320 & 288 & 15.0 \\
\hline August & 4338 & 318 & 13.6 & 4374 & 312 & 14.0 & 4320 & 288 & 15.0 \\
\hline September & 4363 & 318 & 13.7 & 4285 & 306 & 14.0 & 4320 & 288 & 15.0 \\
\hline October & 4410 & 330 & 13.4 & 4403 & 306 & 14.4 & 4409 & 306 & 14.4 \\
\hline November & 4512 & 354 & 12.7 & 4569 & 336 & 13.6 & 4427 & 300 & 14.8 \\
\hline December & 4356 & 324 & 13.4 & 4368 & 312 & 14.0 & 4326 & 288 & 15.0 \\
\hline Average & 4377 & 328 & 13.3 & 4366 & 311.5 & 14.0 & 4350 & 294 & 14.8 \\
\hline
\end{tabular}

Table 5 Mean and standard deviation propulsion power \%MCR

\begin{tabular}{|c|c|c|c|c|c|}
\hline Scenario & $\mathrm{V} 14 \kappa 4$ & $\mathrm{~V} 14 \kappa 7$ & $\mathrm{~V} 15 \kappa 10$ & Fixed14 & Fixed15 \\
\hline January & $59 \pm 6$ & $73 \pm 10$ & $80 \pm 11$ & $75 \pm 9$ & $90 \pm 8$ \\
\hline February & $54 \pm 9$ & $70 \pm 11$ & $78 \pm 10$ & $74 \pm 16$ & $86 \pm 10$ \\
\hline March & $63 \pm 8$ & $72 \pm 12$ & $81 \pm 9$ & $74 \pm 14$ & $85 \pm 9$ \\
\hline April & $55 \pm 10$ & $76 \pm 12$ & $84 \pm 7$ & $81 \pm 15$ & $90 \pm 11$ \\
\hline May & $57 \pm 7$ & $63 \pm 6$ & $78 \pm 7$ & $63 \pm 6$ & $78 \pm 7$ \\
\hline June & $58 \pm 5$ & $62 \pm 4$ & $76 \pm 5$ & $62 \pm 3$ & $76 \pm 4$ \\
\hline July & $59 \pm 4$ & $61 \pm 3$ & $74 \pm 3$ & $61 \pm 3$ & $74 \pm 3$ \\
\hline August & $57 \pm 5$ & $62 \pm 3$ & $75 \pm 3$ & $63 \pm 4$ & $77 \pm 4$ \\
\hline September & $55 \pm 4$ & $58 \pm 2$ & $73 \pm 3$ & $59 \pm 2$ & $73 \pm 3$ \\
\hline October & $62 \pm 8$ & $76 \pm 11$ & $83 \pm 13$ & $85 \pm 14$ & $93 \pm 10$ \\
\hline November & $62 \pm 16$ & $73 \pm 19$ & $80 \pm 13$ & $83 \pm 15$ & $91 \pm 11$ \\
\hline December & $57 \pm 8$ & $65 \pm 7$ & $80 \pm 8$ & $66 \pm 7$ & $82 \pm 8$ \\
\hline Average & $58 \pm 9$ & $67 \pm 11$ & $78 \pm 9$ & $70 \pm 14$ & $83 \pm 10$ \\
\hline
\end{tabular}

Figure 13 shows the initial voyage for the October scenario. Leaving Japan, the sea passage model chooses a route North of the great circle route, which is the assumed route in scenarios Fixed14 and Fixed15. Up to $t=50$ the observed sea states are approximately equal in all cases. Although the target speed is set to 14 knots for the $\mathrm{V} 14 \kappa 4$ and $\mathrm{V} 14 \kappa 7$ scenarios, both choose intervals of higher velocities, 15 and 16 knots respectively. From $t=50$ a storm forms in the path of the great circle route. Since scenarios Fixed14 and Fixed15 have fixed route and speed, the vessel is essentially sailing blind, thus no action is taken to avoid the storm. The consequence is that at $t=70$ the vessels in scenarios Fixed14 and Fixed 15 are in the middle of the storm, resulting in considerable speed loss. In contrast, the sea passage module has avoided the storm by heading North. Table 7 shows that for the October scenario the average $H_{\mathrm{s}}$ are significantly higher for the scenarios without the sea passage model, which has a substantial effect on propulsion power and fuel consumption in Tables 5 and 6, respectively. Note also that the sea passage model varies the speed according to the current and future sea states. In the calm sea states from $t=0$ to $t=40$, the sea passage model applied a higher speed than the target speed of 15 knots for the V15 10 . Speed management is done considering a deterministic horizon of $72 \mathrm{~h}$ in the present work, meaning that the sea passage model planned for the storm occurring at $t=70$ at departure.

Large differences in route choices were observed between the sea passage model scenarios in Fig. 10 for the November month. This is a direct consequence of cost management decisions. Figure 14 shows snapshots from the November simulations. At $t=60$, the paths generated in all simulations encounter sea states with $H_{\mathrm{s}}$ approximately 5-6 m. The $\mathrm{V} 15 \kappa 10$ scenario chooses a northern route at speeds $16-17$ knots, sailing just outside the harsh condition area at $t=$ 60 . V $14 \kappa 4$ and $\mathrm{V} 14 \kappa 7$ chooses a southern route at lower speeds. This option results in slightly harsher wave conditions, but conserves fuel at a lower speed. At $t=95$, a storm has developed in the path of $\mathrm{V} 14 \kappa 4$ and $\mathrm{V} 14 \kappa 7$, which is kept at a distance by periods of low speeds from $t=35$ to $t$ $=80$. At $t=120$, this storm has moved east covering a larger area of alternative routes for $\mathrm{V} 14 \kappa 4$ and $\mathrm{V} 14 \kappa 7$, and wave conditions to the north, behind $\mathrm{V} 15 \kappa 10$, has deteriorated and is moving south-east. Consequently, $\mathrm{V} 14 \kappa 4$ and $\mathrm{V} 14 \kappa 7$ chooses to sail further south, while $\mathrm{V} 15 \kappa 10$ has a clear path towards destination. Ultimately, V14 $\kappa 4$ and $\mathrm{V} 14 \kappa 7$ sails a significantly longer route and encounters worse conditions 
Table 6 Fuel consumption total [ton] and rate [ton/day]

\begin{tabular}{|c|c|c|c|c|c|c|c|c|c|c|}
\hline \multirow[t]{2}{*}{ Scenario } & \multicolumn{2}{|c|}{$\mathrm{V} 14 \kappa 4$} & \multicolumn{2}{|c|}{$\mathrm{V} 14 \kappa 7$} & \multicolumn{2}{|c|}{$\mathrm{V} 15 \kappa 10$} & \multicolumn{2}{|c|}{ Fixed14 } & \multicolumn{2}{|c|}{ Fixed15 } \\
\hline & Rate & Total & Rate & Total & Rate & Total & Rate & Total & Rate & Total \\
\hline January & 58.2 & 800 & 72.3 & 940 & 80.3 & 1004 & 74.7 & 950 & 92.6 & 1115 \\
\hline February & 53.0 & 743 & 68.9 & 896 & 78.4 & 980 & 74.0 & 962 & 87.0 & 1051 \\
\hline March & 62.1 & 837 & 71.2 & 926 & 81.9 & 1004 & 74.6 & 976 & 86.4 & 1047 \\
\hline April & 54.5 & 790 & 76.1 & 989 & 84.4 & 1055 & 82.7 & 1069 & 92.6 & 1110 \\
\hline May & 55.9 & 754 & 61.8 & 788 & 77.6 & 932 & 62.1 & 789 & 77.2 & 916 \\
\hline June & 56.8 & 752 & 60.3 & 769 & 75.0 & 900 & 60.6 & 770 & 75.8 & 900 \\
\hline July & 57.6 & 748 & 59.5 & 758 & 73.1 & 878 & 59.6 & 758 & 73.4 & 871 \\
\hline August & 55.8 & 739 & 60.3 & 783 & 74.7 & 896 & 61.9 & 787 & 76.5 & 907 \\
\hline September & 54.1 & 717 & 57.1 & 728 & 72.2 & 866 & 57.2 & 728 & 72.4 & 860 \\
\hline October & 60.9 & 838 & 75.4 & 962 & 84.9 & 1083 & 85.9 & 1132 & 94.7 & 1197 \\
\hline November & 62.2 & 917 & 73.2 & 1025 & 80.2 & 1002 & 84.1 & 1093 & 94.0 & 1159 \\
\hline December & 56.2 & 759 & 63.8 & 830 & 80.4 & 965 & 65 & 826 & 81.9 & 974 \\
\hline Average & 57.3 & 784 & 66.7 & 868 & 78.7 & 965 & 70.3 & 905 & 83.8 & 1011 \\
\hline
\end{tabular}

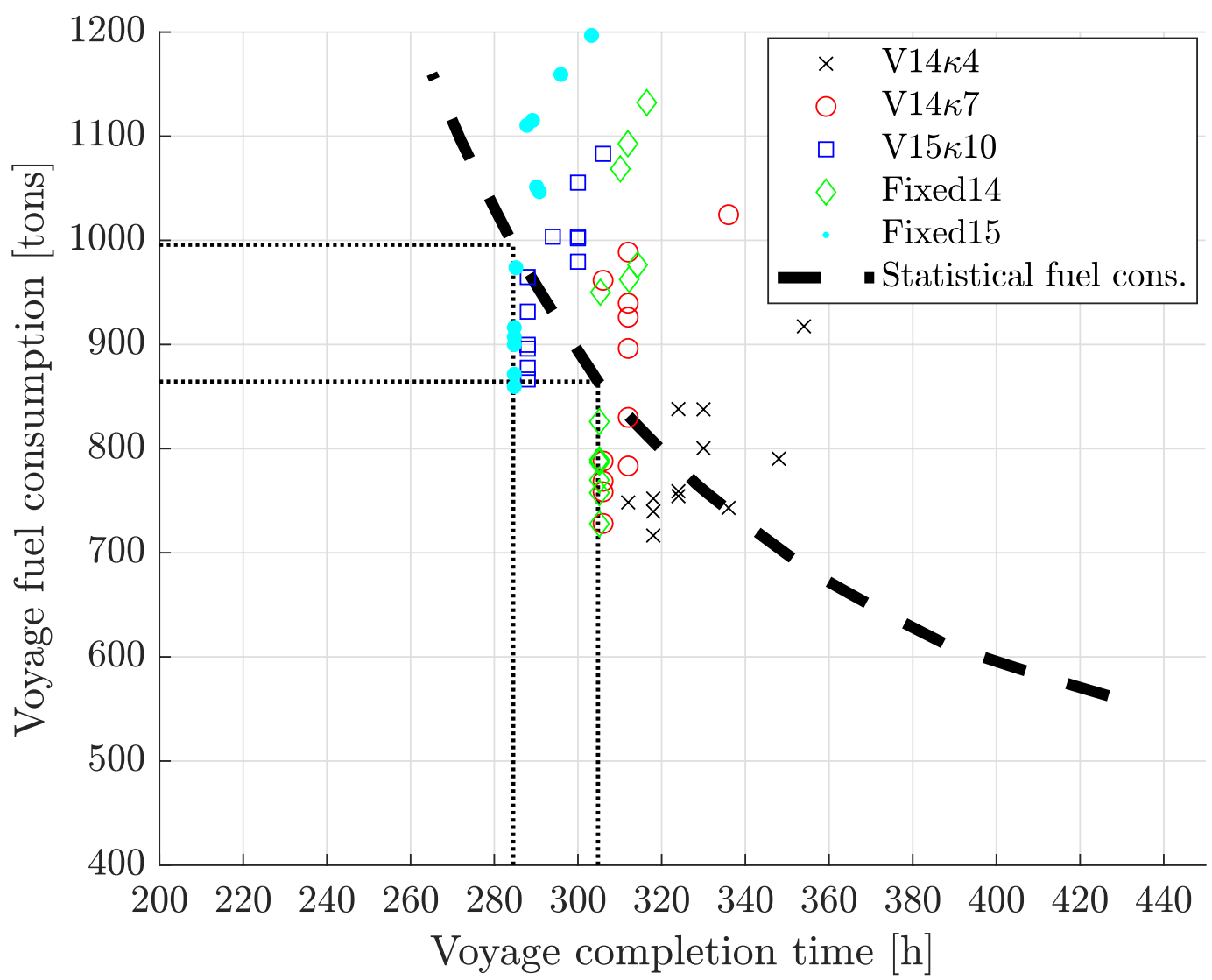

Fig. 11 Operational diagram for the sea passage simulation results

than V15א10, see Tables 4 and 7. This occurs as a consequence of choosing the southern route at departure and no weather information beyond $h$ hours.

The difference in speed management between the scenarios is illustrated in Fig. 15. The sea passage model applies ship speeds on different ranges depending on target speed and delay cost rate. For the V $15 \kappa 10$ scenario, the requested speed is limited to the range 12-17 knots. Even though harsh sea states occur, the sea passage model does not reduce speed below 12 knots, causing several occurrences of speed loss shown in Fig. 15. Note that the speed is set for a duration of $u_{\mathrm{p}}$ hours, and that such harsh conditions 
Table 7 Mean observed $H_{\mathrm{s}}[\mathrm{m}]$ for each simulated scenario

\begin{tabular}{llllll}
\hline Scenario & V14 4 & V14 7 & V15 10 & Fixed14 & Fixed15 \\
\hline January & 3.1 & 3.2 & 3.4 & 3.3 & 3.6 \\
February & 3.4 & 3.5 & 3.5 & 3.8 & 3.7 \\
March & 3.4 & 3.5 & 3.4 & 3.8 & 3.5 \\
April & 3.3 & 3.7 & 3.7 & 4.2 & 3.8 \\
May & 2.1 & 2.2 & 2.2 & 2.2 & 2.2 \\
June & 1.9 & 1.9 & 2.0 & 1.9 & 2.0 \\
July & 2.0 & 1.9 & 1.9 & 1.9 & 1.9 \\
August & 1.7 & 1.7 & 1.7 & 2.0 & 1.9 \\
September & 1.5 & 1.5 & 1.7 & 1.5 & 1.7 \\
October & 3.5 & 3.5 & 3.8 & 4.3 & 4.1 \\
November & 4.1 & 4.1 & 3.5 & 4.2 & 4.0 \\
December & 2.6 & 2.7 & 2.7 & 2.8 & 2.8 \\
Average & 2.7 & 2.8 & 2.8 & 3.0 & 3.0 \\
\hline
\end{tabular}

are not necessarily present for the entire period. V14 $\mathrm{k}$ also experiences some instances of speed loss in the same area, but this was left out of the figure as it is contained in a very small area. V14 4 does not experience speed loss, which indicates a more passive and careful sea passage behaviour. This shows how the sea passage model generates differences in sea passage behaviour by regulating the ship speed- sea state relationship. The threshold for lowering ship speed is different depending on the modelled incentive for reaching port of destination on schedule. For high delay cost, the model accepts high fuel consumption at higher speeds in presence of harsh sea state conditions, while the speed is reduced more frequently for low delay cost.

\section{Discussion}

This section discusses the findings in Sect. 5 and evaluates the abstraction and applicability of the sea passage model applied in the case study. First, the contribution to ship system interpretation using simulation is discussed. The discussion is concluded with a review on modelling abstractions and their possible influence on the results.

\subsection{Interpreting performance during sea passage}

The motivation for developing this model was to improve the relevance for virtual testing sea passage scenarios by controlling how the vessel model executes its voyage. This is done by providing an explicit logic in the model that governs the vessel's progress along the route. The basis for this logic is the desire to keep operational costs at a minimum, which in the model is done using an optimization routine to search for the optimal heading and throttle commands. By varying
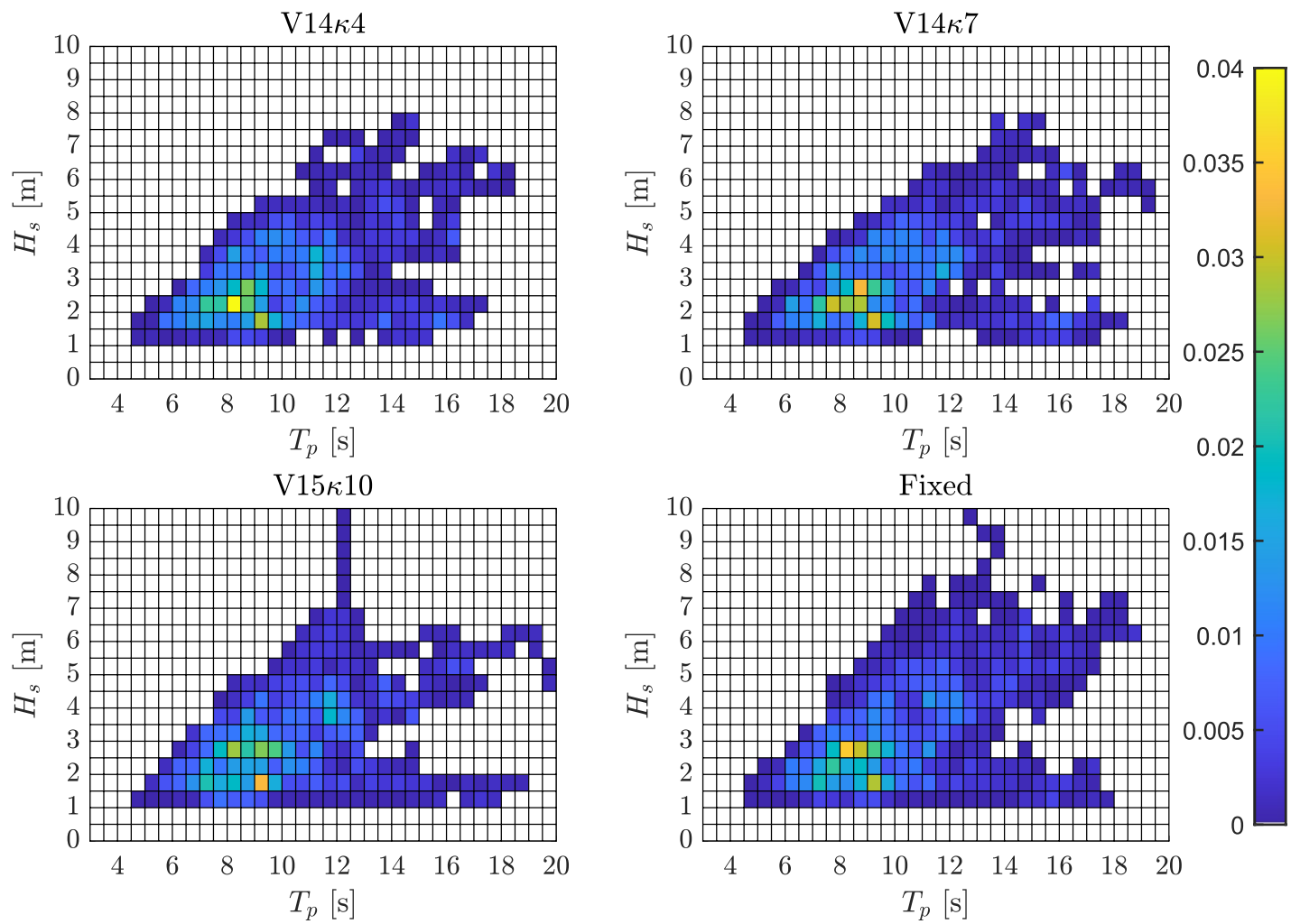

Fig. 12 Scatter diagram of observed sea states in each scenario. Fixed14 and Fixed15 plotted in the same plot 

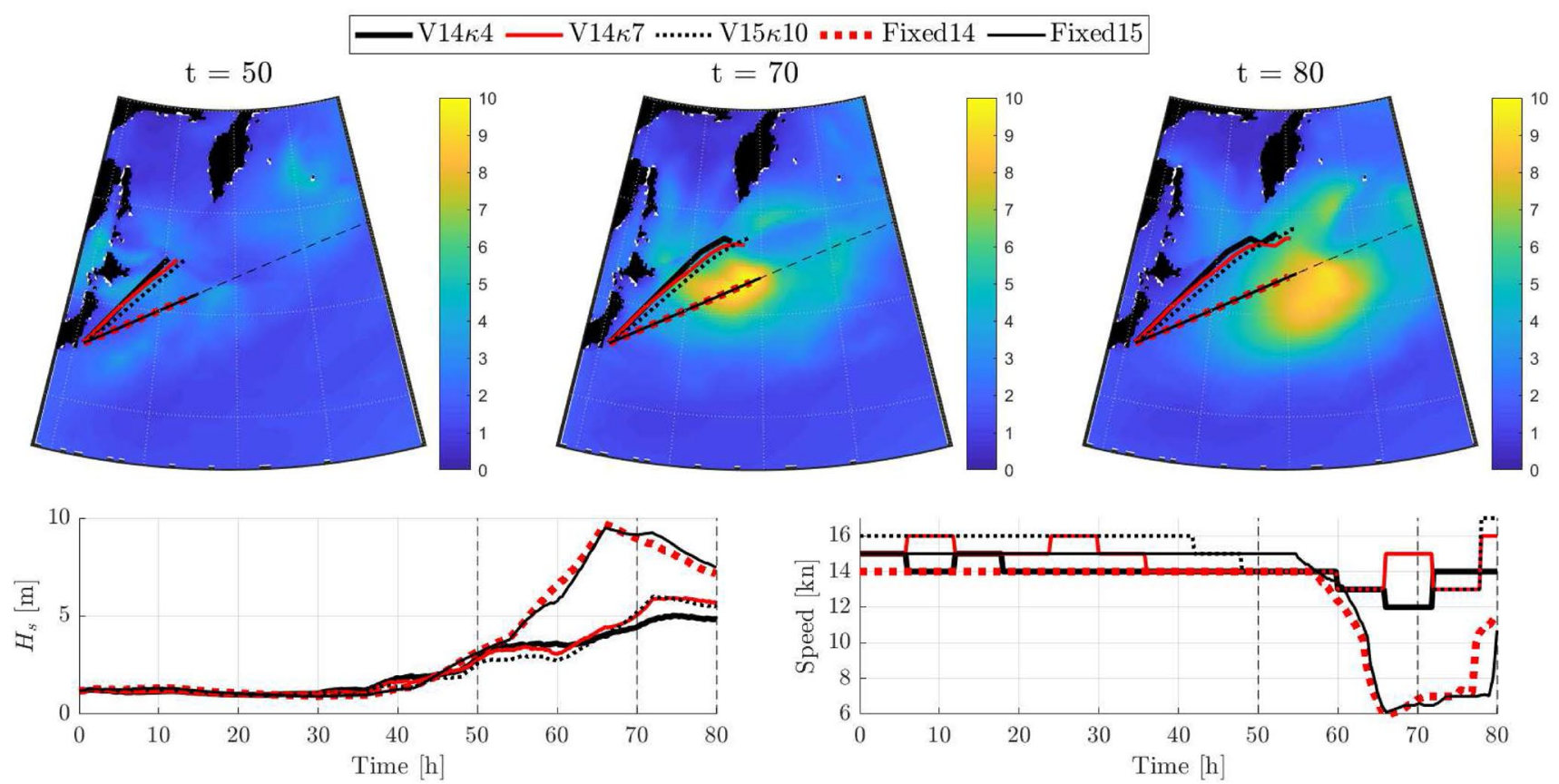

Fig. 13 Snapshots for the October simulation with time series of $H_{\mathrm{s}}$ and vessel speed. The sea passage model adjusts the vessel path North of the occurring storm, affecting experienced sea states and applied speed
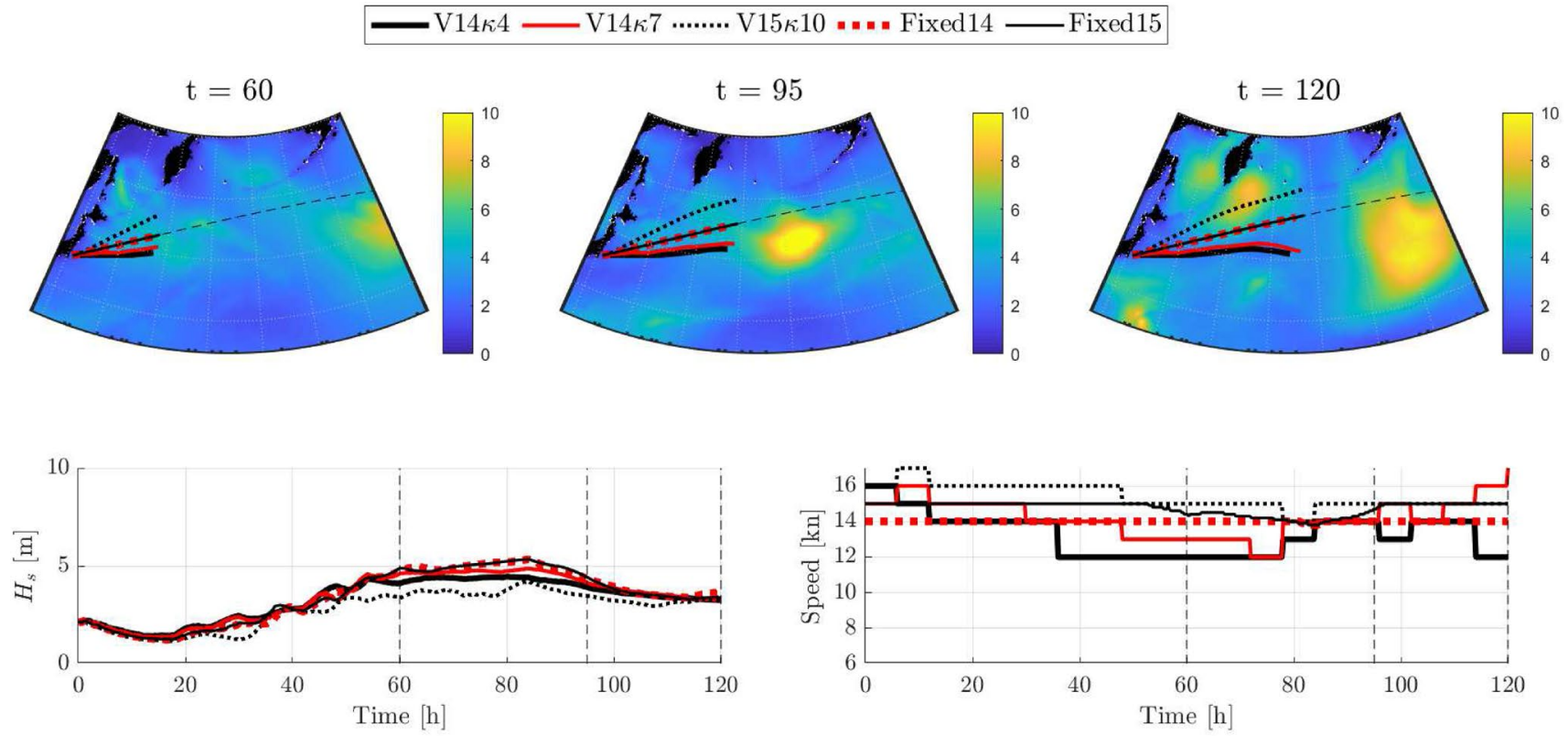

Fig. 14 Snapshots for the November simulation with time series of $H_{\mathrm{s}}$ and vessel speed. The sea passage model adjusts the vessel path relative to the occurring storm according to the target speed and delay cost rate

the conditions from which the cost is calculated, target speed and delay costs, a significant difference in voyage fuel consumption and required power is observed.

A cherished attribute for simulation tools and virtual testing schemes is the freedom associated with constructing models and specifying detailed scenarios of interest. It is believed that this ability to test designs in more relevant conditions will unveil new and valuable insights. However, this freedom comes with responsibilities. In this paper it has been shown how much simulation estimates of propulsion 


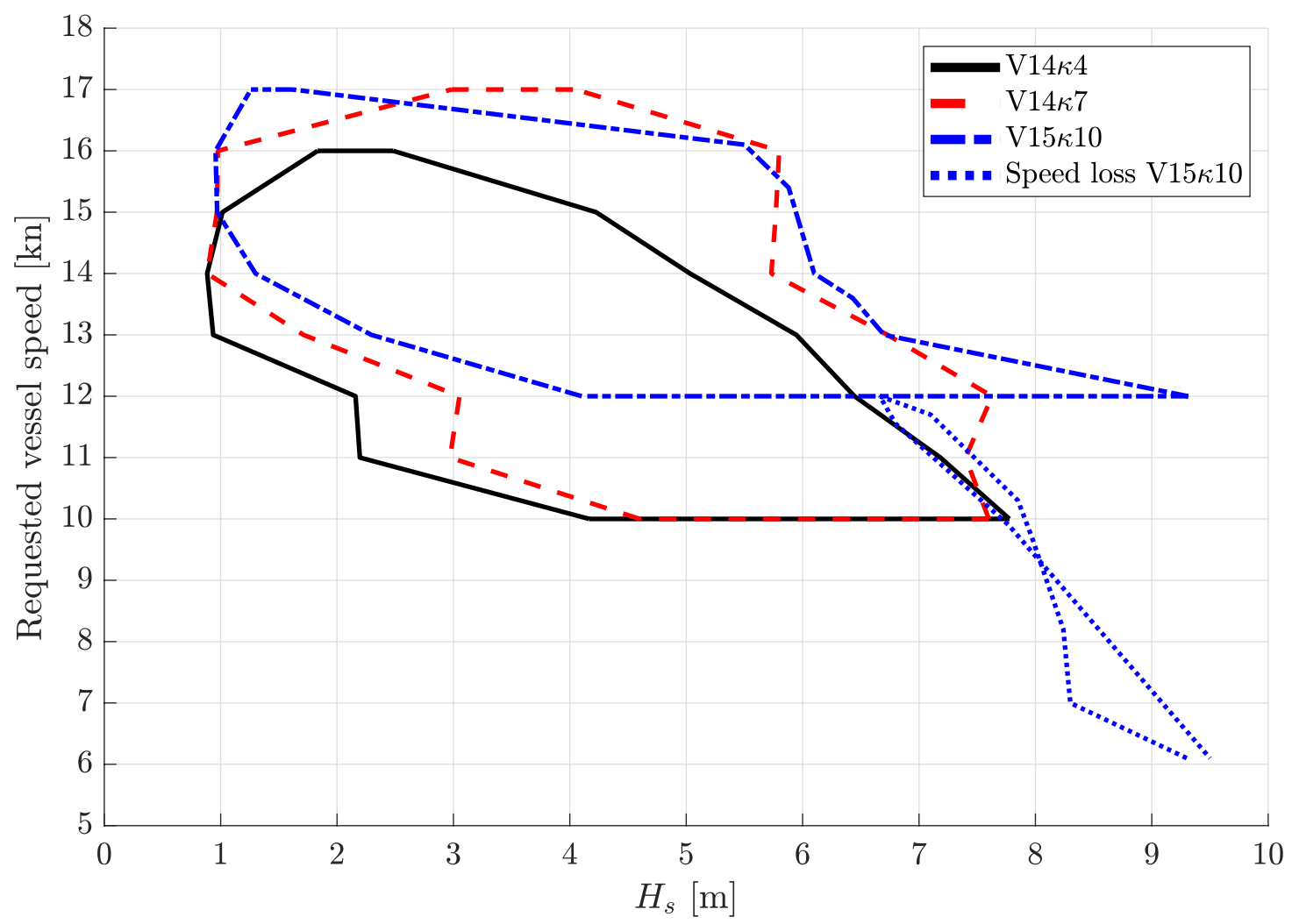

Fig. 15 Speed management characteristics for each scenario using the sea passage model. The enclosed areas contain $H_{\mathrm{s}}$ and requested ship speed combinations sampled from each scenario simulation. Simulation results from all seasons

power and fuel consumption estimates vary for a sea passage for minor adjustments in the scenario description. Also, this work demonstrates that neglecting the route and speed decisions made during the voyage can result in erroneous interpretation of vessel performance and resource requirements. This adds to previous studies looking into e.g. fuel consumption estimate uncertainties and model fidelity of ice and wave models with the intention of unveiling how inadequate modelling may affect the understanding of engineering systems $[21,22,33]$.

The case study concerns only single voyages, i.e. one passage for each month and in each scenario. To achieve a good understanding regarding fuel consumption and propulsion power, a long-term simulation is required to capture the inherent variability of occurring sea states. As mentioned in the introduction, the wave climate observed by the vessel may differ from the metocean statistics as a consequence of weather routing. The results show that by applying the sea passage model one obtains significantly different wave climates for scenarios where harsh weather is present along the route. If the scope is to simulate sea passage voyages over several years this difference can cause bias. The magnitude of this bias is scenario specific. Differences occur mainly in scenarios where rough sea states are present. It is also likely that shorter routes may not be affected to a significant degree since there is a limited area where relevant routes can be established. Such scenarios are however just as susceptible to speed adjustments as longer routes. The recommendation following this work is therefore to consider whether route and speed variation is a viable alternative for the operation in question, and implement similar models to take these effects into account.

\subsection{Sea passage abstraction}

Modelling implies a description of the real system through a process of abstraction. In this paper, the KVLCC 2 and its power production system exposed to waves is described using a table look-up model based on time domain simulations. Further, a model for scenario generation is proposed which controls the vessel's sea passage behaviour. The scope of this paper is the generation and application of relevant scenarios so this discussion will concern the optimization procedure and its interaction with the simulator.

Figure 2 shows the approach for establishing a model for sea passage scenario generation. The idea of applying an optimization routine for handling operational and tactical voyage decisions arises from the ship's function 
in the economical domain, i.e. as a mode of transportation for cargo. There is no doubt that ship owners and operators strive to lower cost, and that fuel cost is a major part of operating budgets for deep sea ships. The delay cost may be interpreted in two ways. First, it may be part of the agreement between the ship owner and cargo owner specifying a time window for cargo delivery or pick-up, in which case a linear cost model with rate $\kappa$ might be insufficient depending on the agreement [34]. Second, one might consider it as a model for the available slack before departure on subsequent voyages. Ship owners prepare schedules considering a time horizon of weeks or months, and late arrivals can cause a knock-on effect affecting future vessel and fleet scheduling [35]. The application of fuel and delay cost as a basis for decision making in the model is therefore considered reasonable. However, there are other factors which affect ship routes and speed. Figure 10 shows the resulting routes for each simulated month. For February, March and October, the vessel is guided significantly north of the great circle route. This occurs as consequence of harsh weather systems present along the route, causing the model to manoeuvre around. However, a captain may be reluctant to go that far north during fall and winter due to a statistically rougher wave climate and occurrence of sea ice. Whether this is the case is dependent on experience and preference, i.e. subjective considerations. The impact of human factors is difficult to capture in mathematical models, however a risk-based penalty could be considered to control this behaviour. Including potentially dangerous hydrodynamic phenomena in route decision making, such as parametric rolling or ship broaching, could also affect routing decisions. This will require powerful hydrodynamic analysis tools capable of evaluating non-linear loads and responses in rough wave conditions. In addition to being useful for the purpose in this paper, analysis of the occurrence probability for such events can be analysed. Such analyses could for instance support generation of operational guidelines for vessels not able to fulfil requirements in the second generation stability criteria. A review of further considerations and weather routing factors is given in [10].

Further work to replicate operational sea passage scenarios should include comparison towards real world sea passage patterns. In such a study, comparison between simulated ship tracks and speed management could be compared to AIS data to benchmark the model. This will facilitate model validation through ensuring that routes and speeds are replicated in a realistic manner. Further, comparison enables determination of optimization parameters for tuning the model. Delay cost and target speed parameters are for instance likely to vary depending on ship trade. The need to expand the model to include other factors, as discussed above, can also be assessed.
The estimates of the vessel's speed in waves consider voluntary and involuntary speed loss as a function of sea state parameters. Since the intention is to apply this model for testing ship system concepts, evaluated in this paper using fuel consumption and propulsion power, the model for controlling speed and power in waves is vital. Figure 15 shows that the model reduces speed in the presence of harsh sea state conditions in an effort to preserve fuel. This affects interpretation of the required propulsion power for the vessel, and might impact decisions for maximum rating for the installed machinery system. For such evaluations, it is important to keep in mind that the ship must maintain manoeuvrability in harsh weather conditions. Neglecting this lower bound for installed power can cause dangerous situations for ships in operation [36, 37].

The sea passage model decision making process relies on the ability to forecast ship behaviour. In the presented case study, it was assumed that the occurring sea states along all candidate routes are known within a horizon of $h=72 \mathrm{~h}$. Beyond this horizon, it was assumed that no weather forecast is available. All weather forecasting is subject to uncertainty which generally is a function of the lead time between forecast issuance and time of realization. By neglecting this uncertainty, one is assuming that the model is able to make the best decision possible within the observed horizon and route discretization. Weather routing systems onboard ships are subject to this uncertainty, so in this case the presented model represents an abstraction. In addition, an abrupt end to the available information is assumed at the end of the horizon. This limits the sea passage model's ability to make strategic routing decisions. Hence, the simulation model may chose a sea passage strategy which encounters rougher conditions than necessary over time. These assumptions where however implemented as a consequence of the optimization routine's application as part of the simulator. Optimization routines are notoriously time consuming to solve, depending on the size and discretization of the problem. The current model is therefore to be considered a trade-off between computational effort and simulation study scope. Introducing uncertainty in weather forecasts is likely to be included in a future development of the model, but for the purpose of this paper the current implementation is considered to be sufficient. The computational effort must be managed such that the model is applicable in long-term simulators. The present work focuses on how one can utilise optimization to enhance simulator functionality and result quality, and to demonstrate the importance of considering storm avoidance and speed management proactively in the simulator. Work remains to find suitable optimization heuristics and implementations to enhance performance and reduce computing time. This will facilitate expansion of the model in terms of forecast horizon and uncertainty, as well as other factors such as risk and ship loading condition. 


\section{Conclusion}

The present work illustrates the importance of considering sea passage scenarios in simulation-based design of ships, and presents a model capable of producing relevant scenarios based on operational considerations. A case study is presented where voyages over the North Pacific are simulated for varying seasons and vessel delay costs and resulting estimates for fuel consumption and required propulsion power is compared.

The results show that the sea passage model affects understanding of vessel performance and requirements. Fuel consumption and propulsion power is significantly reduced for voyages where rough weather systems are present along the vessel path. By varying the arrival delay cost, different combinations of vessel path and speed is achieved. For scenarios with equal target speed, average fuel consumption estimates varies between 784 and 905 tons for 14 knots, and 965-1011 tons for 15 knots. Average propulsion power estimates for the same scenarios varies between 58 and $70 \% \mathrm{MCR}$ for 14 knots and 78-83\%MCR for 15 knots.

A key advantage is the knowledge of which operational considerations the ship has operated in, enabling evaluation of design decision impact on operation. Using the presented model, the understanding of the fuel consumption and propulsion power estimates is linked to a specific operational target. Further, knowledge is obtained regarding the wave climate and associated operational profile for the machinery system for propulsion during sea passage.

Acknowledgements The authors are grateful for the financial support from the Research Council of Norway through the Centre for Research based Innovation (SFI) Smart Maritime project no. 237917/O30, and for the comments provided by the anonymous reviewers helping to improve this article.

Funding Open Access funding provided by NTNU Norwegian University of Science and Technology (incl St. Olavs Hospital - Trondheim University Hospital).

Open Access This article is licensed under a Creative Commons Attribution 4.0 International License, which permits use, sharing, adaptation, distribution and reproduction in any medium or format, as long as you give appropriate credit to the original author(s) and the source, provide a link to the Creative Commons licence, and indicate if changes were made. The images or other third party material in this article are included in the article's Creative Commons licence, unless indicated otherwise in a credit line to the material. If material is not included in the article's Creative Commons licence and your intended use is not permitted by statutory regulation or exceeds the permitted use, you will need to obtain permission directly from the copyright holder. To view a copy of this licence, visit http://creativecommons.org/licenses/by/4.0/.

\section{References}

1. Bouman EA, Lindstad E, Rialland AI, Strømman AH (2017) State-of-the-art technologies, measures, and potential for reducing GHG emissions from shipping-a review. Transp Res Part D Transp Environ 52:408-421. https://doi.org/10.1016/j. trd.2017.03.022 (ISSN 13619209)

2. Lindstad E, Bø TI (2018) Potential power setups, fuels and hull designs capable of satisfying future EEDI requirements. Transp Res Part D Transp Environ 63:276-290. https://doi.org/10.1016/j. trd.2018.06.001 (ISSN 13619209)

3. Skjong S, Rindarøy M, Kyllingstad LT, Æsøy V, Pedersen E (2017) Virtual prototyping of maritime systems and operations: applications of distributed co-simulations. J Mar Sci Technol 78:1-19. https://doi.org/10.1007/s00773-017-0514-2 (ISSN 09484280)

4. Bergström M, Erikstad SO, Ehlers S (2016) A simulation-based probabilistic design method for Arctic Sea transport systems. J Mar Sci Appl 15(4):349-369. https://doi.org/10.1007/s1180 4-016-1379-1 (ISBN 9788494392863)

5. Tillig F, Ringsberg JW, Mao W, Ramne B (2017) A generic energy systems model for efficient ship design and operation. Proc Inst Mech Eng Part M J Eng Marit Environ 231(2):649666. https://doi.org/10.1177/1475090216680672 (ISSN 20413084)

6. Sandvik E, Gutsch M, Asbjørnslett BE (2018) A simulation-based ship design methodology for evaluating susceptibility to weatherinduced delays during marine operations. Ship Technol Res 65(3):137-152. https://doi.org/10.1080/09377255.2018.14732 36 (ISSN 0937-7255)

7. Bøckmann E, Yrke A, Steen S (2018) Fuel savings for a general cargo ship employing retractable bow foils. Appl Ocean Res 76:110. https://doi.org/10.1016/j.apor.2018.03.015 (ISSN 01411187)

8. Gunnar AK, Torgeir M (2010) Adding the human element to ship manoeuvring simulations. J Navig 63(4):695-716. https:// doi.org/10.1017/S037346331000024X (ISSN 03734633)

9. Prpić-Oršić J, Vettor R, Faltinsen OM, Soares CG (2016) The influence of route choice and operating conditions on fuel consumption and CO2 emission of ships. J Mar Sci Technol (Jpn) 21(3):434-457. https://doi.org/10.1007/s00773-015-0367-5 (ISSN 09484280)

10. Perera LP, Soares CG (2017) Weather routing and safe ship handling in the future of shipping. Ocean Eng 130(2016):684-695. https://doi.org/10.1016/j.oceaneng.2016.09.007 (ISSN 00298018)

11. Zaccone R, Ottaviani E, Figari M, Altosole M (2018) Ship voyage optimization for safe and energy-efficient navigation: a dynamic programming approach. Ocean Eng 153:215-224. https://doi. org/10.1016/j.oceaneng.2018.01.100 (ISSN 00298018)

12. Lee SM, Roh MI, Kim KS, Jung H, Park JJ (2018) Method for a simultaneous determination of the path and the speed for ship route planning problems. Ocean Eng 157:301-312. https://doi. org/10.1016/j.oceaneng.2018.03.068 (ISSN 00298018)

13. Li X, Sun B, Zhao Q, Li Y, Shen Z, Du W, Xu N (2018) Model of speed optimization of oil tanker with irregular winds and waves for given route. Ocean Eng 164:628-639. https://doi. org/10.1016/j.oceaneng.2018.07.009 (ISSN 00298018)

14. Vettor R, Soares CG (2015) Detection and analysis of the main routes of voluntary observing ships in the North Atlantic. J Navig 68(2):397-410. https://doi.org/10.1017/S0373463314000757 (ISSN 14697785)

15. Vettor R, Soares CG (2016a) Assessment of the storm avoidance effect on the wave climate along the Main North Atlantic routes. J Navig 69(1):127-144. https://doi.org/10.1017/S03734633150004 $8 X$ (ISSN 14697785) 
16. Vettor R, Soares GC (2016) Rough weather avoidance effect on the wave climate experienced by oceangoing vessels. Appl Ocean Res 59:606-615. https://doi.org/10.1016/j.apor.2016.06.004 (ISSN 01411187)

17. Jia H, Adland R, Prakash V, Smith T (2017) Energy efficiency with the application of virtual arrival policy. Transp Res Part D Transp Environ 54(2011):50-60. https://doi.org/10.1016/j. trd.2017.04.037 (ISSN 13619209)

18. Bassam AM, Phillips AB, Turnock SR, Wilson PA (2015) Ship voyage energy efficiency assessment using ship simulators. In: VI International conference on computational methods in marine engineering, volume I, pp 591-604, Rome, Italy. (ISBN 9788494392863)

19. Fu MC (2002) Feature article optimization for simulation: theory vs practice. INFORMS J Comput 14(3):192-215. https://doi. org/10.1287/ijoc.14.3.192.113 (ISSN 1091-9856)

20. Amaran S, Sahinidis NV, Sharda B, Bury SJ (2016) Simulation optimization: a review of algorithms and applications. Ann Oper Res 240(1):351-380. https://doi.org/10.1007/s10479-015-2019-x (ISSN 15729338)

21. Bergström M, Erikstad SO, Ehlers S (2017) The influence of model fidelity and uncertainties in the conceptual design of Arctic maritime transport systems. Ship Technol Res Schiffstechnik 64(1):40-6. https://doi.org/10.1080/09377255.2017.1312856 (ISSN 20567111)

22. Tillig F, Ringsberg JW, Mao W, Ramne B (2018) Analysis of uncertainties in the prediction of ships' fuel consumption-from early design to operation conditions. Ships Offshore Struct 13:13-24. https://doi.org/10.1080/17445302.2018.1425519 (ISSN 17445302)

23. European Centre for Medium-Range Weather Forecasts (2018) ERA5 Catalogue, (2018). https://apps.ecmwf.int/data-catalogues lera5/?class $=$ ea

24. Taskar B, Yum KK, Steen S, Pedersen E (2016) The effect of waves on engine-propeller dynamics and propulsion performance of ships. Ocean Eng. https://doi.org/10.1016/j.ocean eng.2016.06.034 (ISSN 00298018)

25. Yum KK, Taskar B, Pedersen E, Steen S (2017) Simulation of a two-stroke diesel engine for propulsion in waves. Int $\mathbf{J}$ Nav Archit Ocean Eng 9(4):351-372. https://doi.org/10.1016/j.ijnao e.2016.08.004 (ISSN 20926790)

26. Loukakis TA, Sclavounos PD (1978) Some extensions of the classical approach to strip theory of ship motions, including the calculation of mean added forces and moments. J Ship Res 22:1

27. Park D-M, Lee J-H, Jung Y-W, Lee J, Kim Y (2018) Comparison of added resistance in oblique seas by numerical analysis and experimental measurement. In: Proceedings of the twenty-eighth (2018) international ocean and polar engineering conference, $p p$
139-146, Sapporo, Japan. ISBN 9781880653876. http://www. isope.org

28. Valanto P, Hong Y (2015) Experimental investigation on ship wave added resistance in regular head, oblique, beam, and following waves. Int Soc Offshore Polar Eng. https://doi.org/10.1016/j. nucmedbio.2005.08.007 (ISSN 0969-8051)

29. Liu S, Papanikolaou AD (2016) Prediction of the added resistance of ships in oblique seas. In: Proceedings of the twenty-sixth (2016) international ocean and polar engineering conference, pp 495-502, Rhodes, Greece. (ISBN 9781880653883)

30. Jasna P, Odd MF (2012) Estimation of ship speed loss and associated $\mathrm{CO}_{2}$ emissions in a seaway. Ocean Eng 44:1-10. https://doi. org/10.1016/j.oceaneng.2012.01.028 (ISSN 00298018)

31. Taskar B, Yum KK, Pedersen E, Steen S (2015) Dynamics of a marine propulsion system with a diesel engine and a propeller subject to waves. In: ASME 2015 34th International conference on ocean, offshore and arctic engineering volume 7: ocean engineering, St. John's, Newfoundland, Canada. https://doi.org/10.1115/ OMAE2015-41854 (ISBN 978-0-7918-5655-0)

32. DNV GL (2017) DNVGL-RP-C205-Environmental conditions and environmental loads, 2017

33. Sandvik E, Lønnum OJJ, Asbjørnslett BE (2019) Stochastic bivariate time series models of waves in the North Sea and their application in simulation-based design. Appl Ocean Res 82:283-295. https://doi.org/10.1016/j.apor.2018.11.010 (ISSN 01411187)

34. Christiansen M, Fagerholt K, Nygreen B, Ronen D (2013) Ship routing and scheduling in the new millennium. Eur J Oper Res 228(3):467-483. https://doi.org/10.1016/j.ejor.2012.12.002 (ISSN 03772217)

35. Fischer A, Nokhart H, Olsen H, Fagerholt K, Rakke JG, Stålhane M (2016) Robust planning and disruption management in roll-on roll-off liner shipping. Transp Res Part E Logist Transp Rev 91:51-67. https://doi.org/10.1016/j.tre.2016.03.013 (ISSN 13665545)

36. Shigunov V, Papanikolaou A (2015) Criteria for minimum powering and maneuverability in adverse weather conditions. Ship Technol Res 62(3):140-147. https://doi.org/10.1080/09377 255.2015.1104090 (ISSN 20567111)

37. Shigunov V (2018) Manoeuvrability in adverse conditions: rational criteria and standards. J Mar Sci Technol (Jpn) 23(4):1. https://doi.org/10.1007/s00773-018-0536-4 (ISSN 09484280)

Publisher's Note Springer Nature remains neutral with regard to jurisdictional claims in published maps and institutional affiliations. 